\title{
دور البحث والتطوير والابتكار في تنمية مجتمع المعرفة
}

\section{(R \& D) and innovation role in the development of the knowledge society}

نيللى محمود عبيد

مستخلص

تقاس حضارة الأمم بمدى تقدم مستوى التعليم والبحث العلمي الذي يهدف الى احداث تطوير وتتمية من خلال

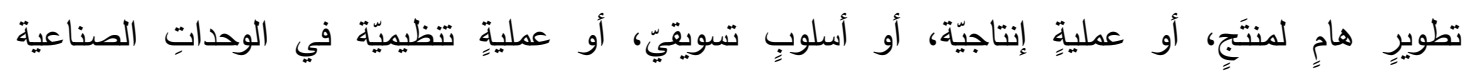
والخدمية؛والذي يطلق عليه الابتكار وفقاً لتوجه مذنظمة اليونسكو, والذي ينعكس في زيادة درجة رئه رفاهية الأمم والدول ككل, ومن ثم ينبغي تطوير البحث العلمي والتعليم باعتباره قضية أمن قومي يؤثر على مستقبل الأجيال

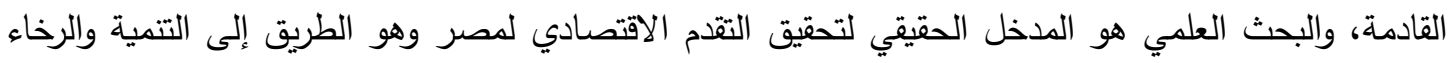

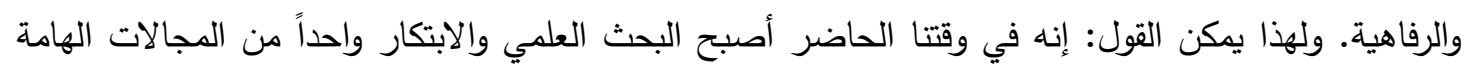
التي تجعل الدول تتطور بسرعة هائلة وتتغلب على كل المشكلات التي تواجها بطرق علمية, وتتتقل سريعاً الى ولى عصر اقتصاد المعرفة.

ومن دراسة واقع البحث والتطوير والابتكار في مصر يتضح أن هناك العديد من المشكلات ونقاط الضعف التي

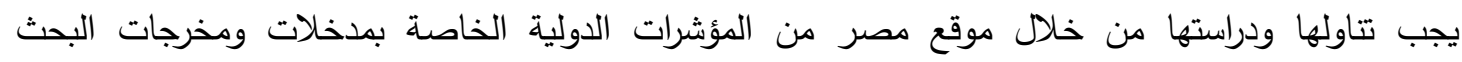
والتطوير والابتكار لتحديد المجالات التي يجب بذل المزيد من الجهد بها ونقاط القوة التي يمكن الاعتماد عليها

$$
\text { في تطوير هذا المجال. }
$$

مقدمة:

لقد نشأ مجتمع المعرفة نتيجة للعديد من الثورات التاريخية في تقنية المعلومات والاتصالات التي أعلت من قيمة العقل والتفكير العلمي, والحرية والديمقراطية والمساواة وأصبح الانسان هو المحور في تكوين مجتمع المعرفة. ومجتمع المعرفة هو مفهوم أكبر من مجرد زيادة الالتزام بالبحث والتطوير.فهو يغطي كل جانب من جوانب الاقتصادات المعاصرة حيث المعرفة هي في صميم القيمة المضافة - من تصنيع التكنولوجيا العالية وتكنولوجيا المعلومات والاتصالات من خلال المعرفة المكثفة والخدمات التي تقدم للصناعات الإبداعية مثل وسائل الإعلام والهندسة المعمارية .... الخ.

ويتطلب تفعيل منظومة المعرفة داخل المجتمع تفعيل عناصر اكتساب المعرفة, والتى تتمثل فى عدة خطوات هى: النفاذ الى مصادر المعرفة, استيعاب المعرفة, استخلاص المعرفة وتتظيمها, توظيف المعرفة, توليد المعرفة الجديدة, اهلاك المعرفة القديمة أو احلالها بالجديد. ويتضح من المراحل السابقة أن جهود معظم الدول النامية وخاصة مصر تتوقف عند مرحلة اقتناء المعرفة دون استيعابها وتوظيفها, وهما اهم مراحل اكتساب المعرفة. ويعد البحث العلمى هو الوسيلة التى يمكن بواسطتها الوصول الى حل مشكلة محدده , أو اكتثاف حقائق جديدة

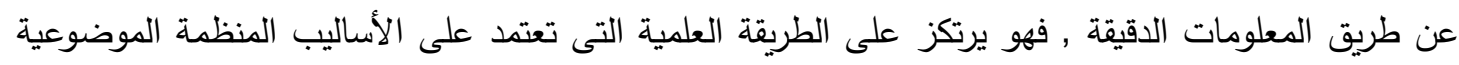

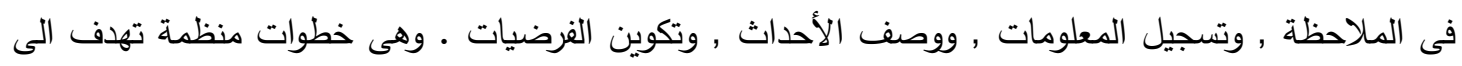


الاكتثاف , وترجمة الحقائق , وهو ما ينتج عنه فهم للاحداث والاتجاهات والنظريات , ويعمل على وجود علم تطبيقى من خلال القوانين والنظريات .

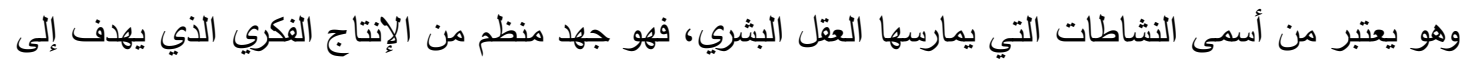

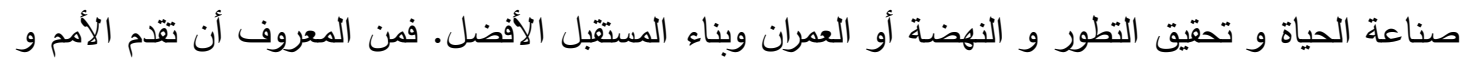

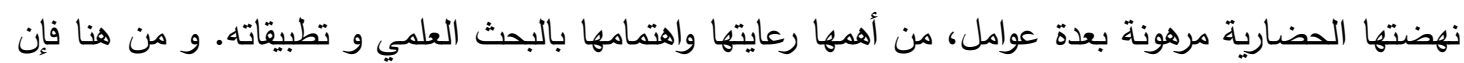

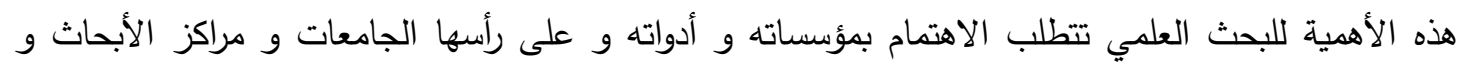

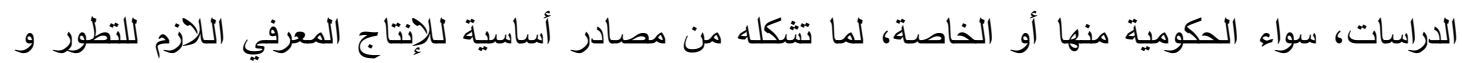

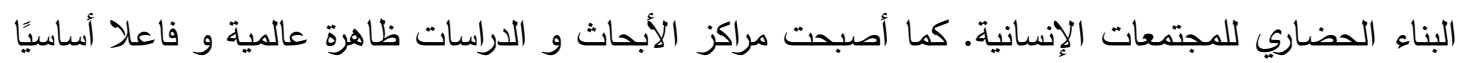

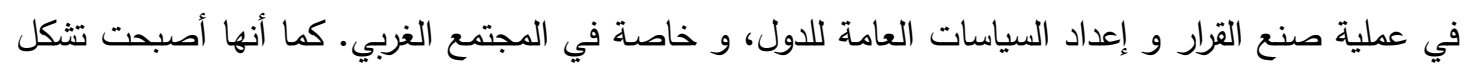
إحدى الظواهر الأساسية للتغيير الحضاري و الإنتاج الفكري و البحث العلمي.

وهناك علاقة وطيدة بين تتمية البحث العلمي والابتكار وبين تتمية المجتمع, فتوجه الأبحاث العلمية للابتكار العلمي والبحوث التطبيقية تؤدي لعائد اقتصادي ومن هنا نشأت فكرة استاد الاقتصاد والتتمية التكنولوجية إلى لى لـاني قاعدة من البحث والتطوير العلمي والتكنولوجي.

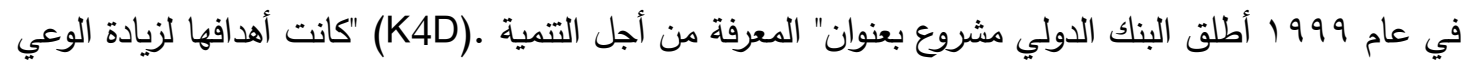

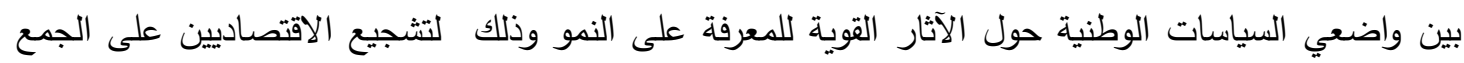

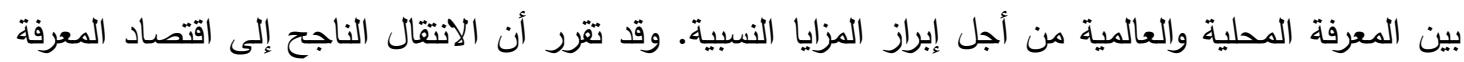

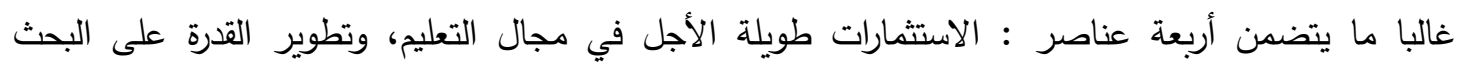
والابتكار، وتحديث البنية التحتية للمعلومات وخلق بيئة اقتصادية مواتية.

ويعتبر البحث العلمى والدراسات العليا موضوعان مرتبطان فلا تزال وظيفة البحوث الأكاديمية مصدراً رئيسياً

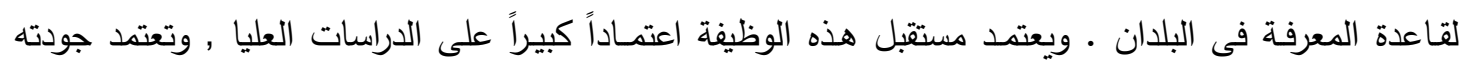

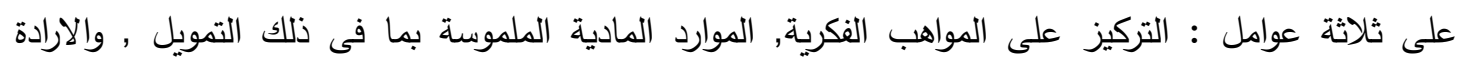
الحكومية .

وتعتبر الجامعة البحثية هى المحور أو المركز الذى يربط بين السياسات المحلية والموازنات الحكومية , بما لها

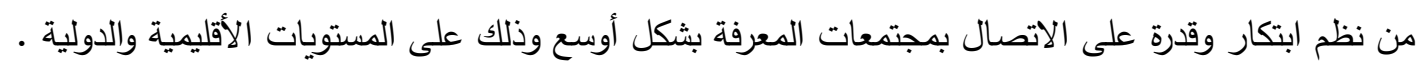

\section{مشكلة البحث :}

ليس هناك خلاف على أهمية البحث العلمى والتطوير والابتكار وأثثه على تقدم الأمم , وهنا ييرز تساؤل هام يجب الاجابة علية وهو , هل البحث العلىى والتطوير والابتكار فى مصر يكفل تحقيق التقدم المنشود ودعم لهم القدرة على الانتقال الى اقتصاد المعرفة ؟ بهو البهابه

وينثأ عن هذا التساؤل التساؤلات الفرعية التالية:

- - ما هو دور البحث والتطوير والابتكار في الانتقال الي مرحلة اقتصاد المعرفة؟ - ما هي المؤشرات الدولية والعربية المستخدمة في الحكم على جودة البحث والتطوير والابتكار ؟ - - ما هو واقع البحث والتطوير والابتكار في مصربه 
تهدف الدراسة إلى توضيح أهمية البحث العلمي والتطوير والابتكار ودورة فى حل مشكلات المجتمع وتحقيق التتمية الاقتصادية , بهدف الانتقال بالدولة الى عصر اقتصاد المعرفة مما يترتب علية زيادة القدرة التتافسية

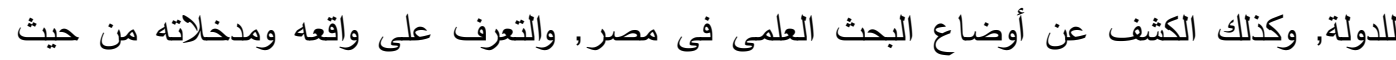
الوضع الحالى للمؤسسات البحثية والموارد المالية والبشرية الخاصة بالبحث العلمى فى مصر لهر أهمية البحث:

Research, من المعترف به على نطاق واسع أن نظام البحث والتطوير والابتكار development, And innovation

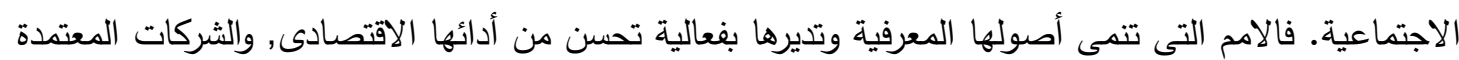
على المعرفة تتفوق دائماً في أدائها على تلك التي يقل فيها التركيز على المعرفة، والأفراد المتمتعون بحصيلة أكبر من المعرفة يحصلون عادةً على وظائف مرتفعة الأجور . وتشكل الاستثمارات في البحث والتطوير والابتكار، والتعليم والتدريب، وغير ذلك من الأصول غير المادية حجر الزاوية لاقتصاد المعرفة الحديث. ويعتبر

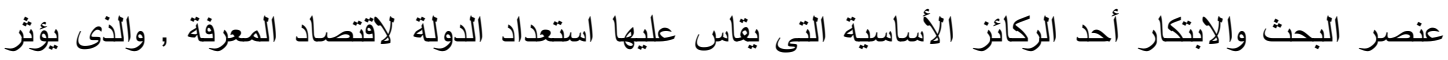

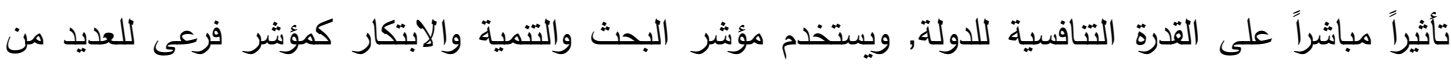

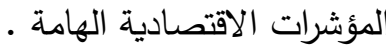

منهجية البحث:

سوف يتم الاعتماد على المنهج الوصفى التحليلى فى قراءة واقع البحث العلمى فى مصر من حيث مدخلات

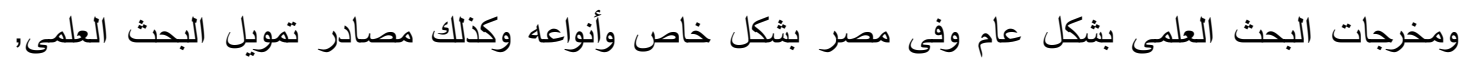

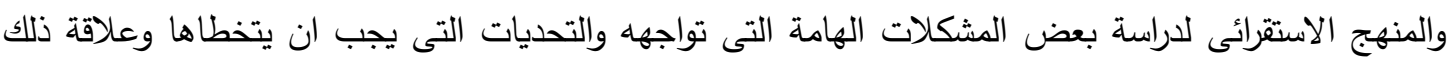
بالتمية المستدامة, , حتى نصل الى استيضاح تام للوضع القائم, وكذلك تحديد موقع مصر من مؤشر اقتصاد

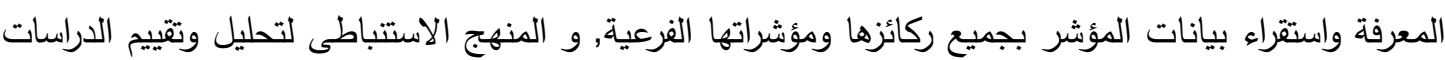

وحتى يتسنى لنا معالجها الموضوع المختار محلا للبحث وفي ضوء ما له من أهميه فقد تم تقسيم البحث إلى

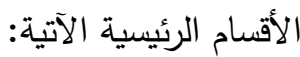

المبحث الأول: مجتمع المعرفة وعلاقته بتحقيق التتمية المستدامة

$$
\text { المبحث الثاني: واقع البحث العلمي والابتكار في مصر }
$$

المبحث الثالث: دور البحث العلمي والابتكار في دعم المعرفة في مصر 


\section{المبحث الأول: مجتمع المعرفة وعلاقته بتحقيق التنمية المستدامة}

$\underline{\underline{a}}$

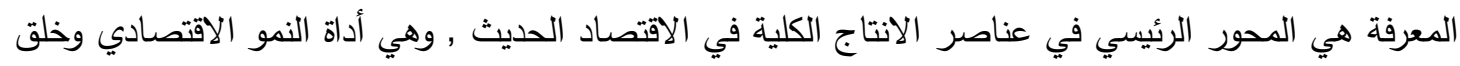
فرص العمل وبناء الاقتصاد المعاصر الذي يطلق عليه اقصاد المعرفة. وقد تضاعفت أهمية المعرفة في الآونة الأخيرة خاصة بعد التطورات العلمية والتكنولوجية في العقود الأخيرة وظهور ما سمي بالعولمة. وأصبح انتاج ونقل المعرفة هو ركيزة التمية.

وتتيح القدرة على التخزين, والمشاركة, وتحليل المعرفة من خلال الشبكات والمجتمعات باستخدام تكنولوجيا المعلومات والاتصالات الجديدة للشركات استغلال خصائص فريدة من نوعها للمعلومات لكسب ميزات تتافسية. وربما تكون الخاصية الأكثر أهمية هى أن المعرفة تعتبر مورد اقتصادي متجدد, حيث لا يتم استنفاذ المعرفة من

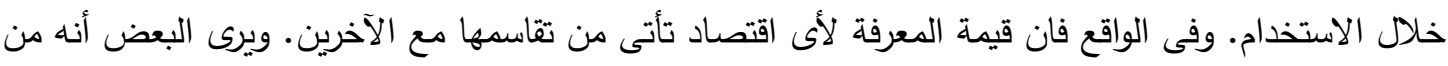
السمات الرئيسية المميزة لاقتصاد المعرفة هو نشر تقنيات جديدة لاستغلال المعرفة الضمنية بشكل أكثر انتظاماً. ويعتقد بعض الكتاب أن المعرفة هي سلعة عامـة. وتعتبر المعرفة مورد اقتصـادي متجدد حيث لا يتم استتفاد

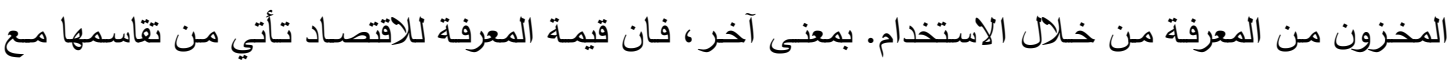

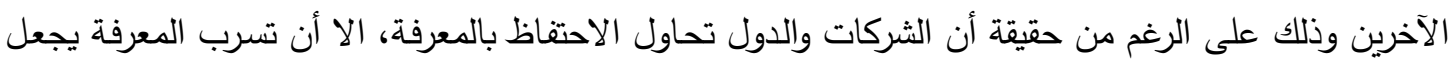

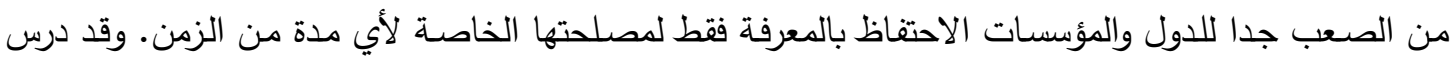
(Foray, 2004) لاقتصاديات المعرفة. وركز انتباهه على الصراع بين الهدف الاجتماعي من كفاءة استخدام المعرفة المنتجة وبين الههف و الدافع لدى المنتجين الخاصين من المعرفة.

\section{Y Knowledge Society مجتمع المعرفة}

ظهر مفهوم مجتمع المعرفة لأول مره في منتصف الستينات من القرن الماضي عندما كانت تحدث مناقشات وجدال حول التتاقضـات والعيوب أو العقبات التي تواجـه المجتمع الصناعي مثل التناقضـات الخاصـة بالموضـة

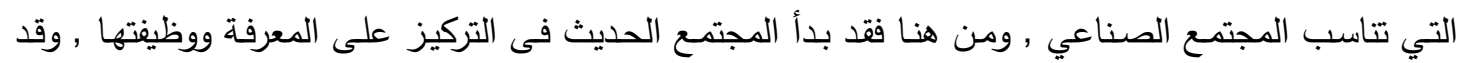

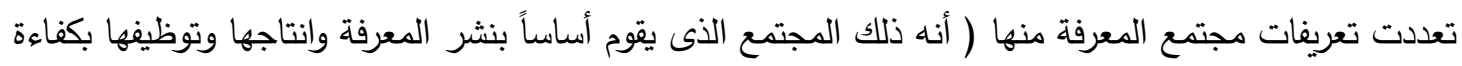

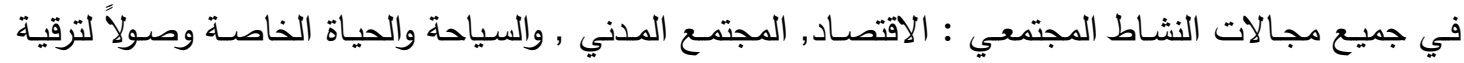

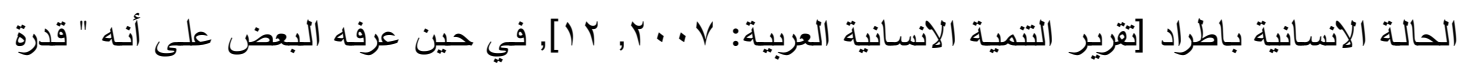
نوعية على التنظيم وايجاد آليات راقية وعقلانية في مجال التسيير , وترتيب الحياه والتحكم في الموارد المتاحة, وحسن استثمارها وتوظيفها, وخاصة ايلاء الموارد البشرية الموقع الملائم في تحديد النمو الاقتصادي, كما يعنى ولئ

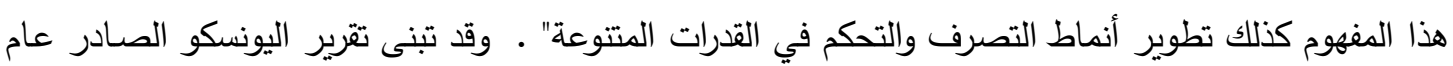

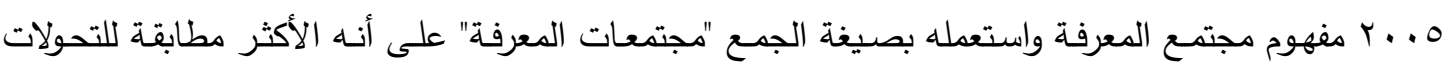
الجارية في عالم يعتمد على البعد التقني , كما يثكل الاقتصاد الجديد وشبكات الاتصـال المظهرين الرئيسيين

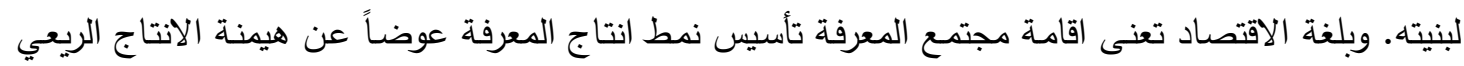

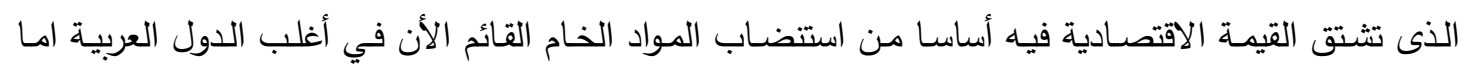


مباشرة في الدول النفطية أو اشتقاقاً من غيرها نتيجة للاعتماد على المعونات وتحويلات العاملين من هذه الدول. أما المعرفة فهي تمثل مورد متجدد يمكن الاعتماد عليه في تحقيق التتمية المستدامة. وفي مجتمع المعرفة لم تعد الجامعات محتكرة لانتاج المعرفة الأساسية, فارتباط البحث العلمي , والصناعة بالجامعة أصبحت مختلفة الآن , حيث أصبح هناك العديد من المؤسسات تثترك في هذه المنظومة, وبالتالي لم لم تعد الجامعات هي المحرك والمنتج الوحيد للمعرفة. وهكذا فان مجتمع المعرفة يحتوي على امكانيات هائلة تمكن

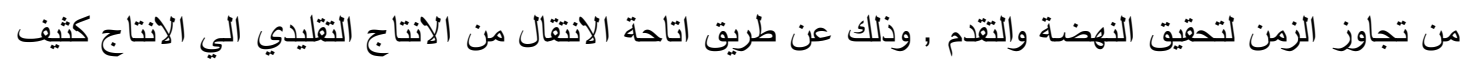

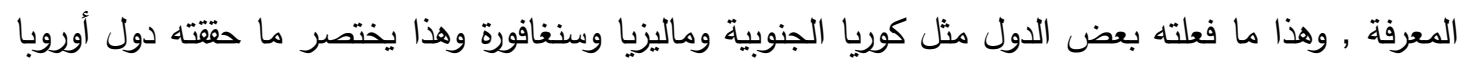

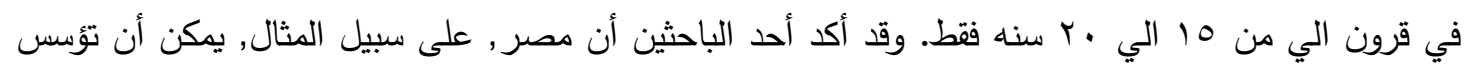

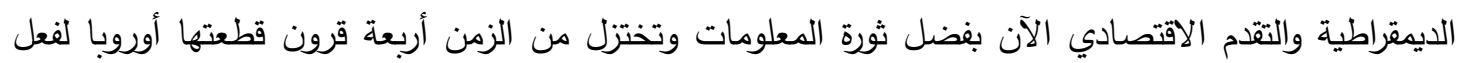

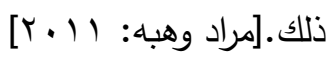

ويتطلب الولوج الي مجتمع المعرفة اتقان الأفراد لمجموعة من المهارات المعرفية, وخاصة الثباب منهم, والتي

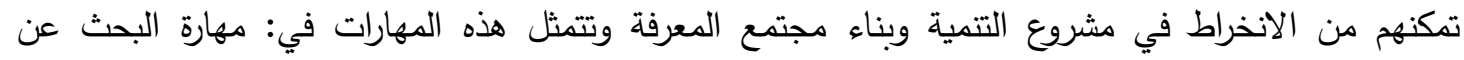
المعلومات ومعالجتها, مهارة التواصل الكتابي, مهارة حل المشكلات, مهارة الاستخدام الهادف والفعال فئلئ للتكنولوجيات الحديثة.

وهناك أيضا مجموعة من المهارات الوجدانية والتي تتمثل في: مهارة معرفة الذات وتقديرها, مهارة طلب

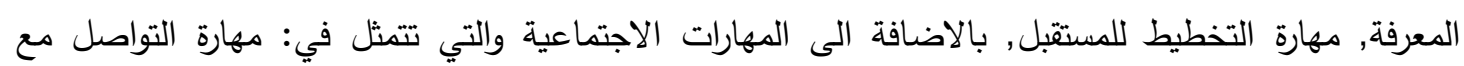
الآخرين, مهارة العمل الجماعي, مهارة المشاركة في الحياة العامة.

\section{ب- المعرفة والنمو الاقتصادي}

لقد أكدت الكتابات التي تتاولت النمو الاقتصادي على توسيع المعرفة بوصفها دافع رئيسي لاحداث النمو. وقد استمدت الأبحاث هذا الاستتاج في وقت مبكر من مفهوم الباقي تresidual والذى يتبقى بعد أن يتم توزيع المساهمات فى النمو على رأس المال والعمل. وفيما بعد حدثت تعديلات نتيجة التوسع فى مفهوم رأس المال الثابت ليثمل رأس المال غير المادي. وكذلك اكتثاف الدوافع الكامنة وراء الابتكار من قبل الكتابات الخاصة

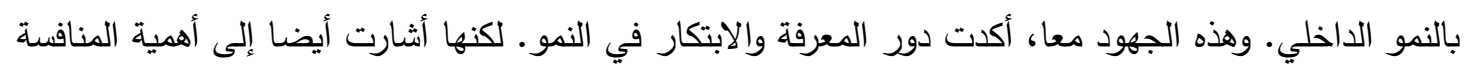

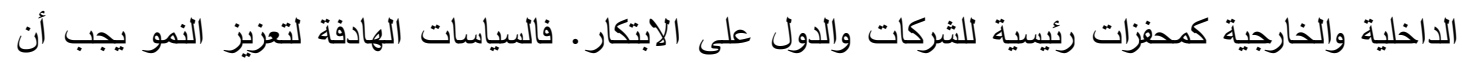
تنظر إلى جانب المبالغ المتتثرة في البحث والتتمية R \& D , والى العمالة المدربة والمنتجات النهائية والأسواق المالية.

ان القدرة على التخزين, والمشاركة, وتحليل المعرفة من خلال الثبكات والمجتمعات باستخدام تكنولوجيا المعلومات والاتصالات الجديدة تتيح للشركات استغلال خصائص فريدة من نوعها للمعلومات لكسب مئن فيزات

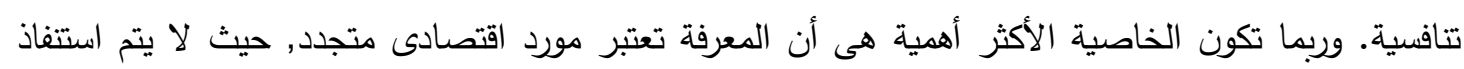

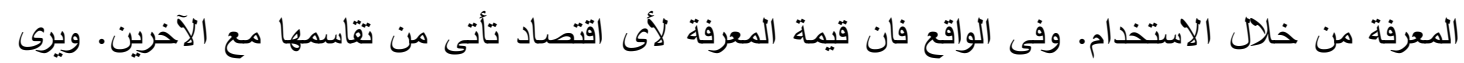

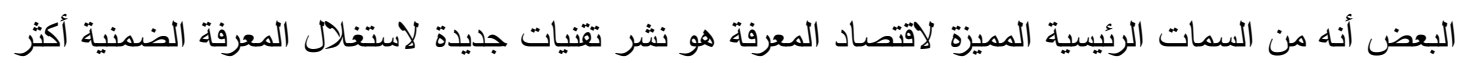


ويعتّد بعض الكتاب أن المعرفة هي سلعة عامة. وتعتبر المعرفة مورد اقتصادى متجدد حيث لا يتم استنفاد

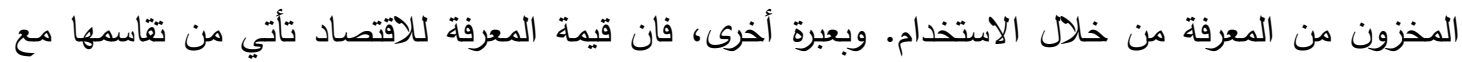

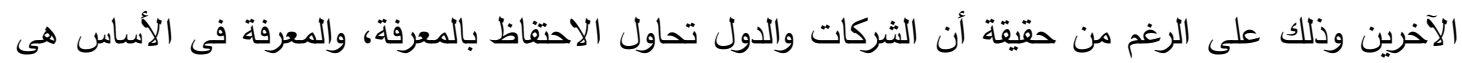

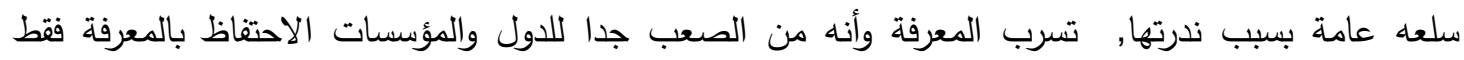

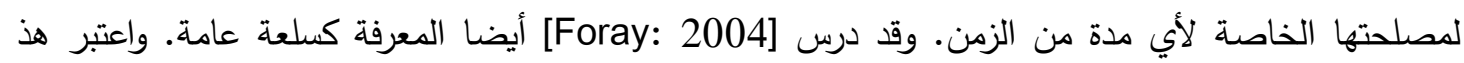
الجانب هو المعضلة الرئيسية لاقتصاديات المعرفة. وركز انتباهه على الصراع بين الهرف الاجتماعي من كفاءة استخدام المعرفة المنتجة وبين الهدف و الدافع من المنتجين الخاصين من المعرفة.

ع - اقتصاد المعرفة

لقد أجريت الكثير من الأبحاث في العقد الماضي حول الإنتاجية التى أدت الى النمو الاقتصادي ومحدداتها.

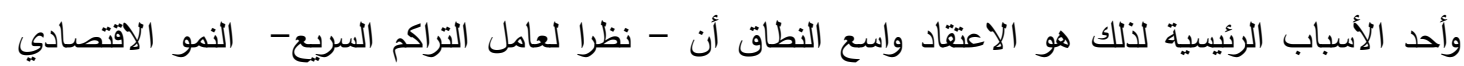

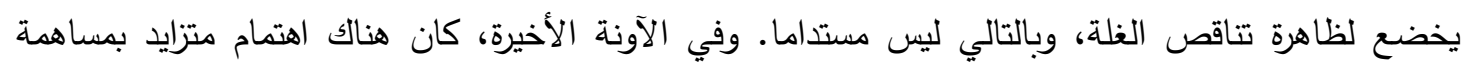

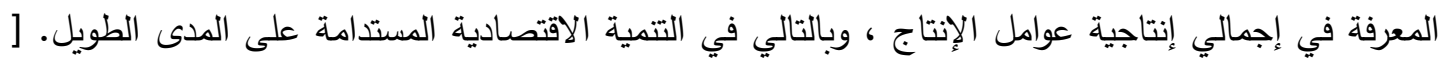

[Sundać, Krmpotić: 2011,105-141

و قد اصبحت درجة التقدم تقاس بالفارق بين مدى اكتساب المعرفة والقدرة على اكتسابها ومن المعلوم أن هناك

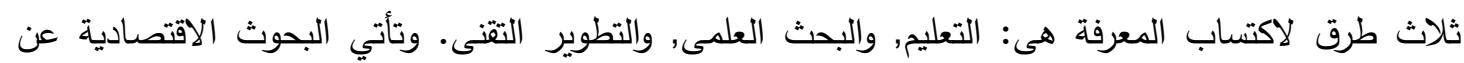

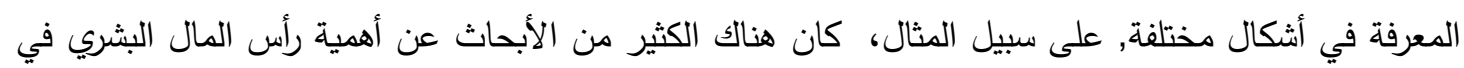

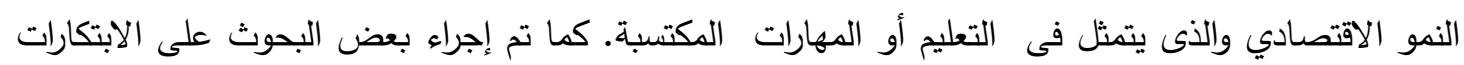
و R \& D البحث والتتميه ) التي تؤدي إلى التكنولوجيات الجديدة، مما أدى في نهاية المطاف الى زياده في التي

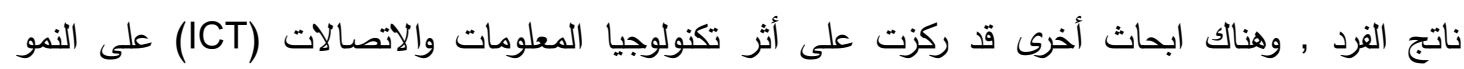
الاقتصادي.

ويعتبر تطبيق المعرفة في مجالات مثل ادارة الأعمال والابتكار ، \& D والبرمجيات وتصميم المنتجات، وعلى مستوى البشر فى التعليم والمهارات ، تعتبر الآن واحدة من المصادر الرئيسية للنمو في الاقتصاد العالمي . ولقد أضحى اقتصاد المعرفة (Knowledge Economy) يمثل رافدا معرفيا جديدا سواءً على صعيد النظرية

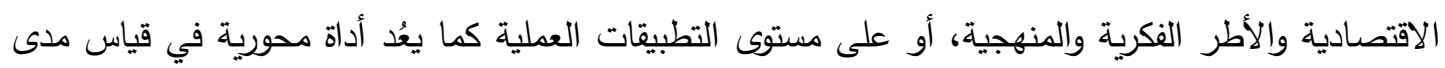
قدرة الدول على حيازة أسباب التقدم وامتلاك ناصية مقوماته اللازمة لنجاح خططها وبرامجها للتمية الاقتصادية

الثاملة.

و يطرح اقتصاد المعرفة جملة من التساؤلات التي أفرزت دعوة عامة استهدفت الباحثين والدارسين وأصحاب القرار والسياسيين لضرورة وضع إطار نظري محكم يضبط أبعاده التأصيلية على مستوى الفكر الاقتصادي ويجسد آلية تطبيقه ، لإعطاء الواقع صورة حقيقية تساهم في عمليات ضبط ملامح السياسة الاقتصادية

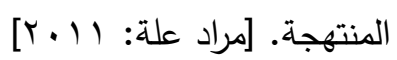

وقد أشار البنك الدولى فى تقرير التتمية العالمية 1999/1991 عن "المعرفة والتتمية" الى أن تضييق الفجوه المعرفية Knowledge Gap بين مختلف الدول من ناحية وبين الشرائح والجماعات المختلفة داخل الدولة 
الواحدة من الناحية الأخرى, هو هدف رئيسى يواجه كل المجتمعات والمؤسسات المهتمة بالتتمية الدولية مثلما يواجه الحكومات الوطنية ذاتها, وان مله هذه الفجوة المعرفية هو خطوة اساسية فى طريق التتمية الاقتصادية,

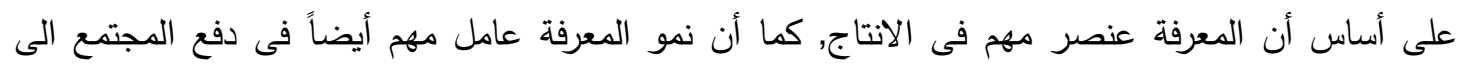

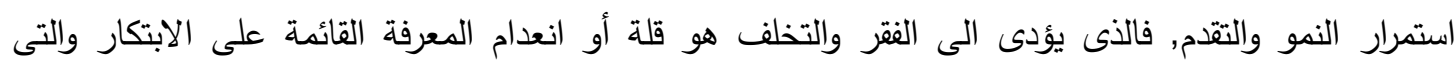
تساعد على تحقيق المنافسة المستدامة.

وفي عام 1999 أطلق البنك الدولي مشروع بعنوان" المعرفة من أجل التتمية . لزيادة الوعي بين

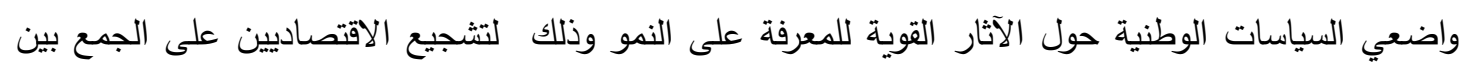
المعرفة المحلية والعالمية من أجل إبراز المزايا النسبية.

Knowledge Assessment Methodology وقد وضع البنك الدولى عام 1999 منهجية لتقييم المعرفة كاطار للدول الأعضاء فيها من أجل تحديد مستوى تتميتها الاقتصادية القائمة على المعرفة ـ وفىى (KAM)

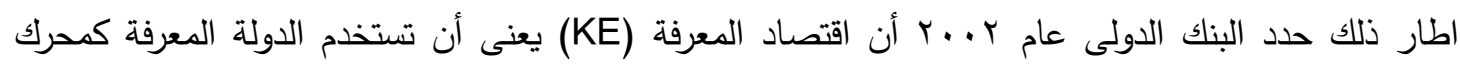
رئيسى للنمو الاقتصادى. وهو أحد أنواع الاقتصاد حيث يتم الحصول على المعرفة , وخلقها ونشرها واستخدامها بثكل فعال لتعزيز التتمية الاقتصادية , والرفاهية الاجتماعية , والقدرة التتافسية للدولة.

ع - أ مفهوم اقتصاد المعرفة

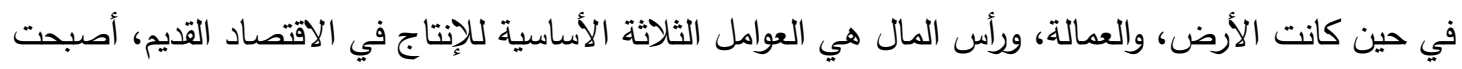

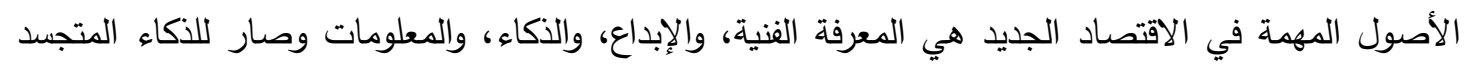

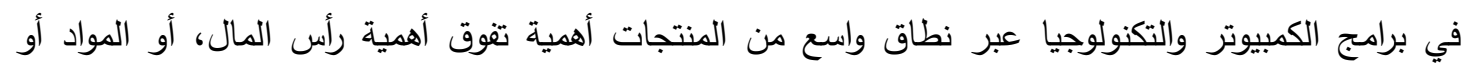

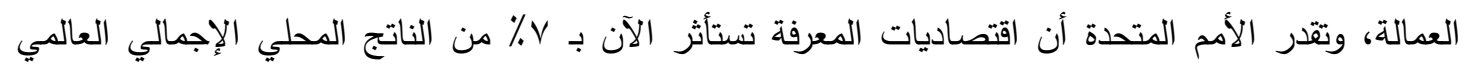

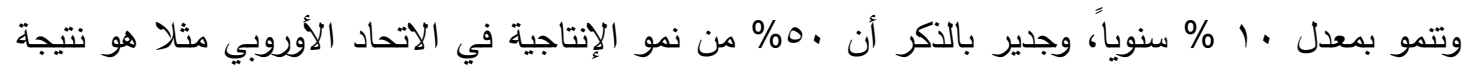

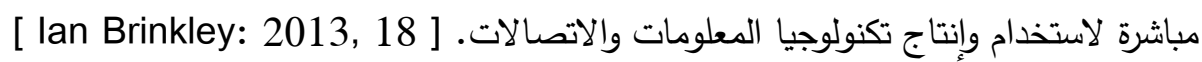
وقد شهد مفهوم اقتصاد المعرفة تطورا كَبيرا فَي العقود القليلة الماضية مع اتساع استخدام شبكة الانترنت والتجارة الالكترونية والدفع الالكتروني، ويقوم هذا الاقتصاد على وجود بيانات يتم تطويرها إلى معلومات، ومن فئن

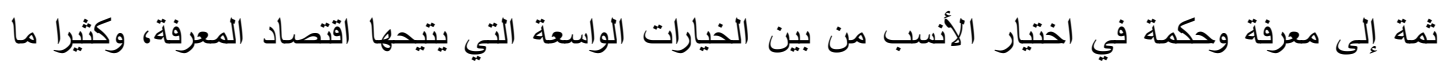
تستخدم مصطلحات متعددة للتأكيد على جوانب مختلفة لاقتصاد المعرفة منها مجتمع المعلومات والاقتصاد، لئه والاقتصاد الرقمي، وشبكة الاقتصاد الجديد أو اقتصاد المعرفة وثورة المعلومات.

وهنا وجب التمييز بين مستويين أو دلالتين مختلفتين لتعبيري " اقتصاد المعرفة" و" الاقتصاد القائم - أو المبني -على المعرفة" حيث أن الدلالة الأولى لتعبير اقتصاد المعرفة هي ما يتعلق باقتصاديات عمليات المعرفة ذاتها، سواءً من حيث التكاليف العملية المعرفية أو الذهنية مثل تكاليف البحوث والتطوير ، أو تكاليف إدارة الأعمال الاستشارية أو إعداد الخبراء وتدريبهح من جهة، وبين العائد أو الإيراد الناتج من هذه العملية باعتبارها عملية

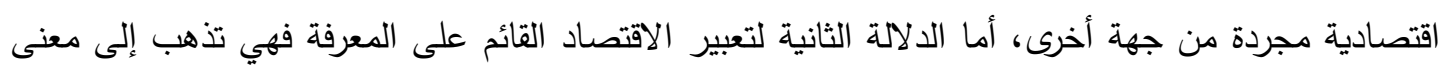
أكثر اتساعا ورحابة بحيث تشمل حجم قطاعات المعرفة والمعلومات والاستثارات الذهنية داخل نسيج الاقتصاد سواءً كان نشاطا سلعيا أو خدميا عينيا كان أو نقدياً. 
ان صعوبة تحديد تعريف لبعض المصطلحات تعتبر ظاهرة منتشرة فى الأدبيات الاقتصاديه , ويواجه اقتصاد

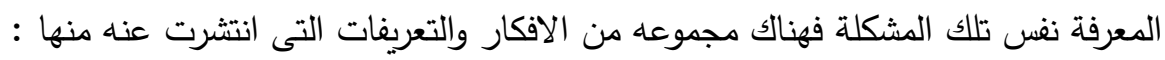
تعرف منظمة التعاون والتتمية اقتصاد المعرفة عن طريق ما يلي: الاقتصادات المبنيه على المعرفة هى الاقتصادات التي تعتمد مباشرة على إنتاج وتوزيع واستخدام المعرفة والمعلومات. و تتميز الاقتصادات القائمة على المعرفة من خلال نمو الاستثمارات في التكنولوجيا العالية، والصناعات ذات التكنولوجيا العالية، والعمال الأكثر مهارة ومكاسب الإنتاجية المرتبطة بها.

وياخذ دور المعرفة - بالمقارنة بالموارد الطبيعية وراس المال المادى وراس المال البشرى منخفض المهارة أهمية كبرى , لذلك فقد اتجهت جميع اقتصاديات منظمة التعاون والتتمية نحو الاقتصاد القائم على المعرفة

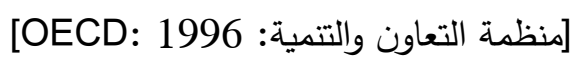
الاقتصاد الذى تحركه المعرفة هو الذي يلعب توليد واستغلال المعرفة فيه الدور الاغلب في خلق الثروة. انها ليست مجرد دحر حدود المعرفة؛ بل هو أيضا استخدام أكثر فعالية واستغلال كل أنواع المعرفة في جميع أنواع

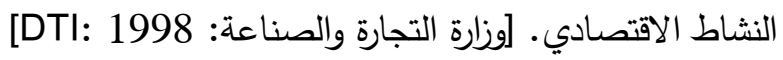
اقتصاد المعرفة هو ما يتم الحصول عليه عندما تستخدم الثركات معا الحاسبات القوية والعقول المتعمه تعليما

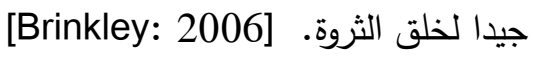
الاقتصادات القائمة على المعرفة هى الاقتصادات التي تكون نسبة الوظائف كثيفة المعرفة عالية، والثقل الاقتصادي لقطاعات المعلومات هو العامل الحاسم، وحصة رأس المال غير الملموس هو أكبر من رأس المال

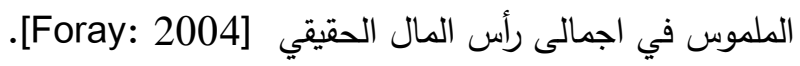
يعتبرالاقتصاد القائم على المعرفة مكون أساسى في خلق القيمة المضافة على أساس استخدام المعرفة (وليس

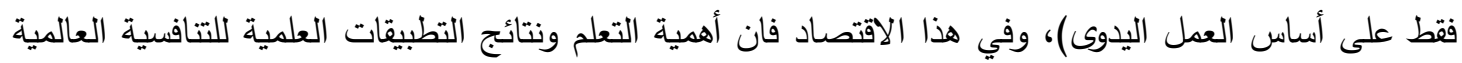
[Jahn et al] آخذ في الازدياد, لقد حان وقت استغلال المعرفه لتلعب الدور الأكبر فى خلق وتوليد الثروة , وهذا لا يعنى فقط اتساع حدود

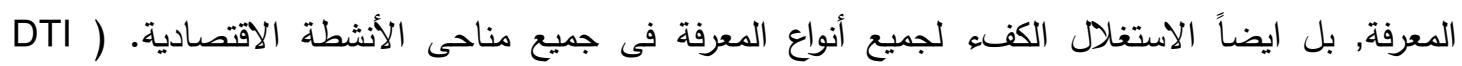
.(1998 Competitiveness White Paper ان فكرة الاقتصاد القائم على المعرفة ليس فقط وصف للصناعات عالية التكنولوجيا , بل أنه يصف وضع مجموعة من مصادر جديده للتنافسية والتى تتطبق على جميع القطاعات, وجميع الثركات, وجميع المناطق, من (New measures for the New Economy, الزراعة وتجارة التجزئة والبرمجيات والتكنولوجيا الحيوية. report by Charles Leadbeater, June 1999) يستند النجاح الاقتصادى بشكل متزايد على الاستخدام الفعال للاصول غير الملموسة مثل المعارف والمهارات

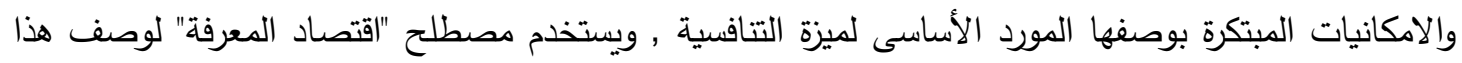
الهيكل الاقتصادى. ESRC, 2005) ان مفهوم "مجتمع المعرفه" هو أكبر من مجرد زيادة الالتزام بالبحث والتتمية R\&D , والابتكار فهو يغطى كل

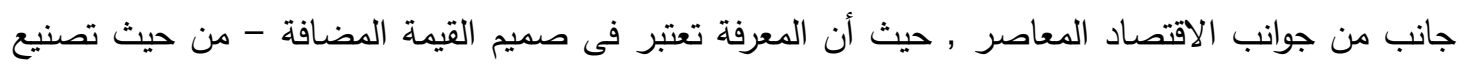


التكنولوجيا العالية وتكنولوجيا المعلومات والاتصالات - من خلال خدمات المعرفة المكثفة التى تدخل فى

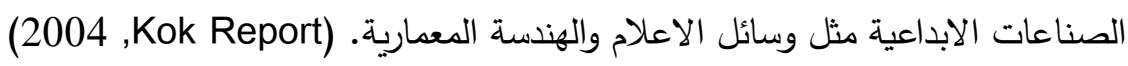
وتعرّف منظمة التعاون الاقتصادي والتتمية (OECD) اقتصاد المعرفة بأنه "الاقتصاد الذي تعدّ فيه المعرفة

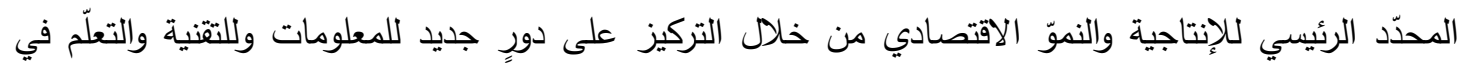

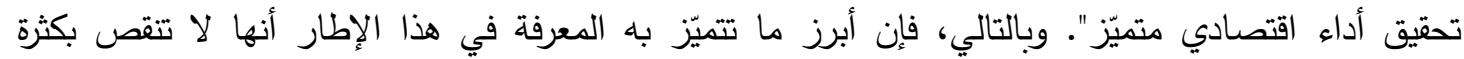

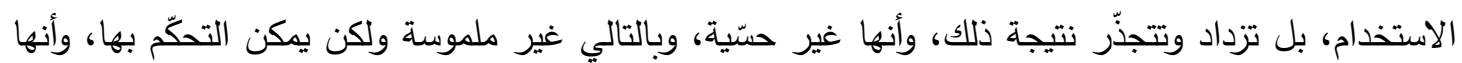

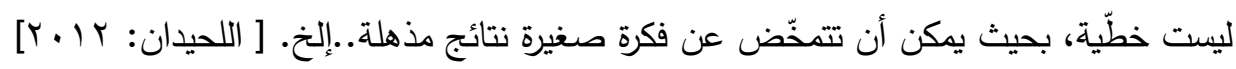
وقد أقر البعض بأن ظهور اقتصاد قائم على المعرفة يعتبر من أهم الانجازات, حيث يقدم "الاقتصاد الجديد"

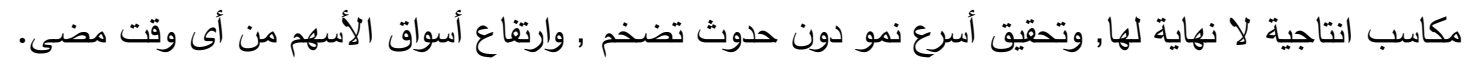
لقد قيل أن ثورة تكنولوجيا المعلومات والاتصالات سمحت لهذه الثركات باستغلال قواعد المعرفة العلمية والتتنية لمنحهم تتافسية غير مسبوقة , مع تراجع مستمر فى المعاملات وتكاليف التجهيز • وأن اقتصاد المعرفة الجديد

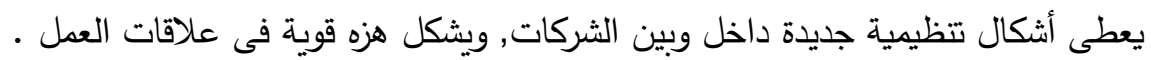
وكرد فعل لهذا الرأي, فقد برز رأى مخالف لذلك عما اذا كان اقتصاد المعرفة موجود حقاً على الاطلاق؟, فقد

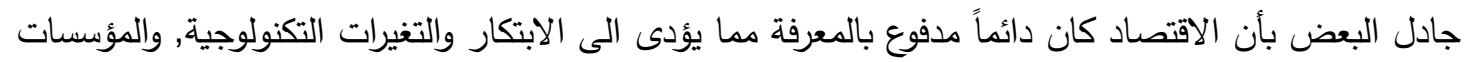

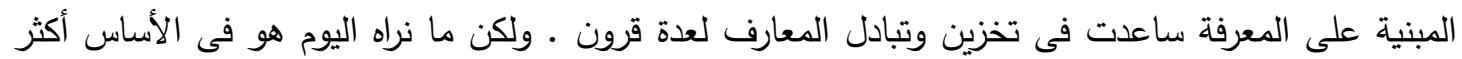
من ذلك بل هو يعمل على نطاق أكبر ووتيرة أسرع. و لو أردنا تقديم تعريف مختصر لاقتصاد المعرفة لأمكننا القول بأنه ذلك الاقتصاد الذي يثكل فيه إنتاج المعرفة وتوزيعها واستخدامها، المحرِّك الرئيسى لعملية النمو المستدام ولخلق الثروة وفرص التوظيف في كل المجالات.

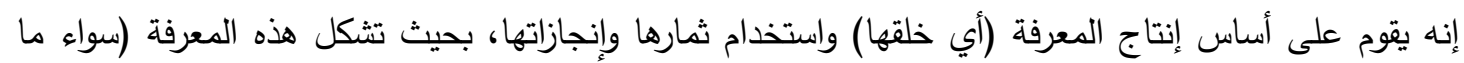
يعرف بالمعرفة الصريحة التي تثتمل على قواعد البيانات والمعلومات والبرمجيات وغيرها، أو المعرفة الضمنية التي يمثلها الإفراد بخبراتهم ومعارفهم وعلاقاتهم وتفاعلاتهم) مصدرا رئيسا لثروة المجتمع ورفاهيته, كما يمكن

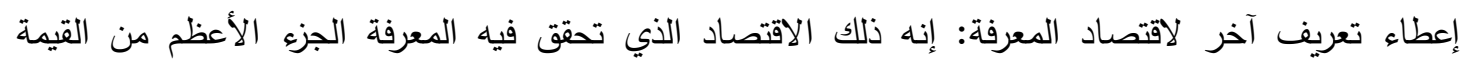
المضافة، وهذا يعني أن المعرفة في هذا الاقتصاد تشكل مكون أَساسي فَّي العملية الإنتاجية كما في التسويق،

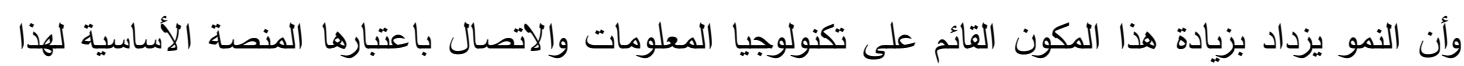
الاقتصاد، ويمكن تعريفه أيضا بأنه نمط اقتصادي متطور قائم على استخدام واسع النطاق للمعلوماتية وشبكات

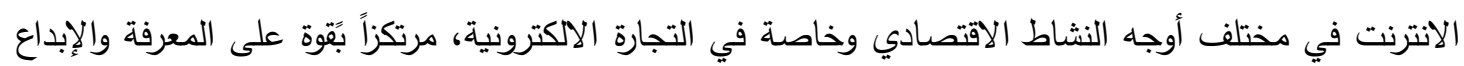
والتطور التكنولوجي خاصة ما يتعلق بتكنولوجيا الإعلام والاتصال. وبناءً على ما تقدم، فإن اقتصاد المعرفة في الأساس يُُصد به أن تكون المعرفة هي المحرك الرئيسي للنمو الاقتصادي، واقتصاديات المعرفة تعتمد على توافر تكنولوجيات المعلومات والاتصال واستخدام الابتكار و

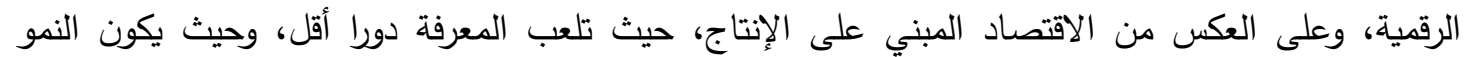

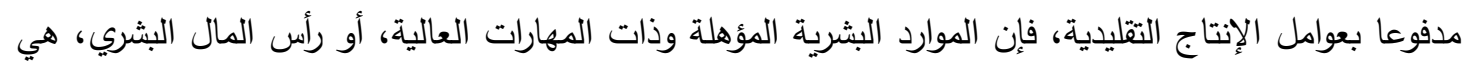

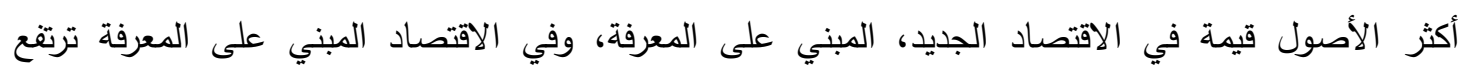


المساهمة النسبية للصناعات المبنية على المعرفة أو تمكينها، وتتمثل في الغالب في الصناعات ذات التكنولوجيا المتوسطة والرفيعة، مثل الخدمات المالية وخدمات الأعمال.

لقد لوحظ أن المعرفة القائمة على الاقتصاد في الوقت الحاضر هى نتيجة للتطور الاقتصادى القائم على المعرفة, وأن الاقتصاد الجديد هو اقتصاد قائم على المعرفة والأفكار , والتى تعتبر العامل الرئيسى للاذدهارهار

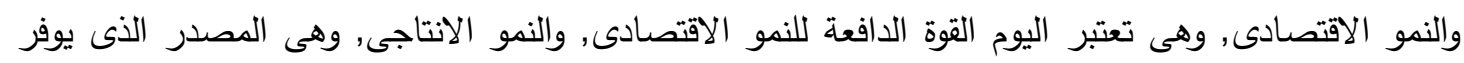

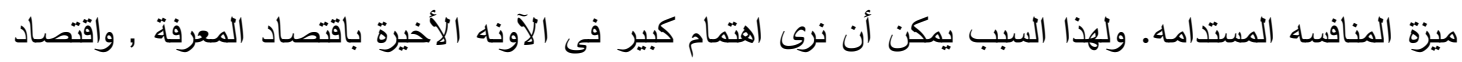
المعلومات والتكنولوجيا ودورها فى النمو الاقتصادى.

وهناك نقاط اختلاف رئيسية بين اقتصاد المعرفة والاقتصاد التقليدى والتى تتمثل فى :

انها ليست اقتصاديات ندرة وانما اقتصاديات وفرة, فهى ليست مثل معظم الموارد التى تستنزف عند استخدامها, فالبيانات والمعلومات يمكن أن تكون مشتركة , وهى تتمو من خلال التطبيق.

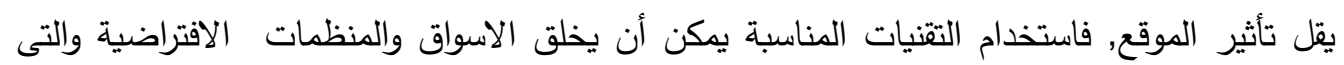
توفر السرعة وخفة الحركة , والعمليات على مدار الساعة وبالتالى الوصول الى العالمية. من الصعب تطبيق القوانين والضرائب وفرض الحواجز الوطنية , فتسريب المعرفة والمعلومات أعلى , والحواجز أقل. المنتجات المصحوبة بالمعرفة يمكن أن تحظى بسعر أعلى مقارنة بالمنتجات منخفضة المعرفة فيما يسمى بكثافة المعرفة. يعتمد السعر والقيمة بشكل كبير على الاطار أو السياق المستخدم به, وبالتالى فان نفس المعلومات أوالمعرفة يمكن أن يكون لها قيمة مختلفة لأناس مختلفين الى حد كبير فى أوقات مختلفة.

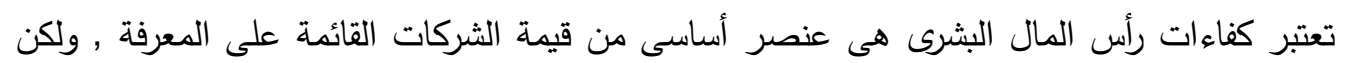

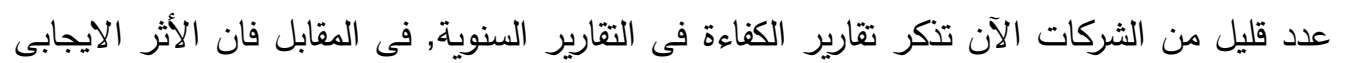
لخفض التكاليف الناتج عن ذلك يظهر جلياً.

\section{צ- خ خصائص اقتصاد المعرفة}

وقد تم تلخيص الخصائص الرئيسية لاقتصاد المعرفة فيما يلى: • الاقتصاد القائم على المعرفة ليس اقتصاداً جديداً بقواعد جديدة. فإنه يمثل طوراً طبيعياً للماضي. • الاقتصاد القائم على المعرفة موجود في جميع قطاعات الاقتصاد. • يتميز الاقتصاد القائم على المعرفة من خلال كثافة عالية ومتزايدة من استخدام تكنولوجيا المعلومات والاتصالات من قبل العاملين تعليما جيدا. • وهناك حصة متتامية من الناتج المحلي الإجمالي المخصصة للمعرفة غير الملموسة مقارنة مع رأس المال

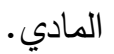
• يتكون اقتصاد المعرفة من منظمات تعتمد على الابتكار . 
• تعيد المنظمات تنظيم العمل لتمكينهم من التعامل مع وتخزين وتبادل المعلومات من خلال ممارسات إدارة المعرفة .

ع - ب تقييم اقتصاد المعرفة

هناك مجموعه من البحوث والأنظمه والتى تضعها المؤسسات والمعاهد الإحصائية الدولية للمؤشرات الخاصة

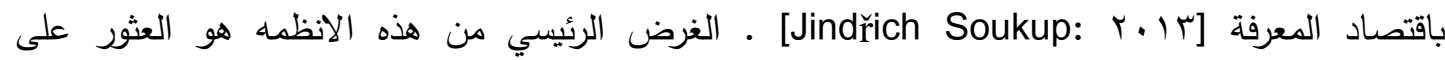

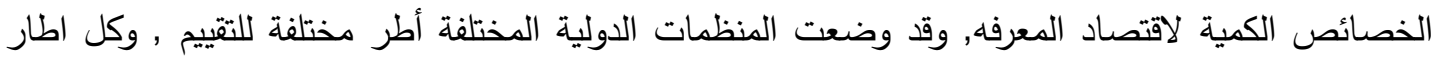
يتميز بعدد من الأبعاد, وكل بعد يتميز بعدد من الخصائص. ومن هذه الأنظمة التى تم استخدامها لمحاولة قياس اقتصاد المعرفة:

American النظام الأول للمؤشرات تم انشاؤه من قبل مؤسسة تكنولوجيا المعلومات والابتكار الأمريكية Information Technology and Innovation Foundation (ITIF) بنشر مؤشر الاقتصاد الجديد للولايات الأعضاء فى الولايات المتحده الأمريكيه , كما تصدر تقريراً لتقييم

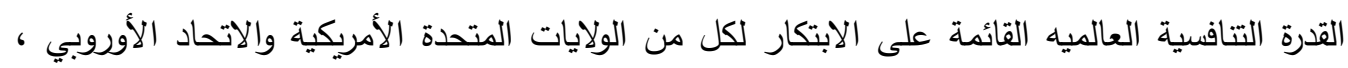

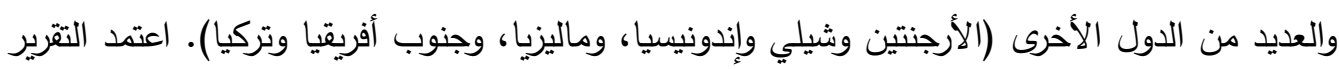

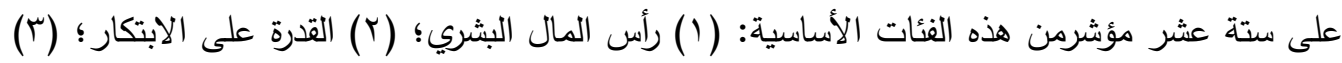

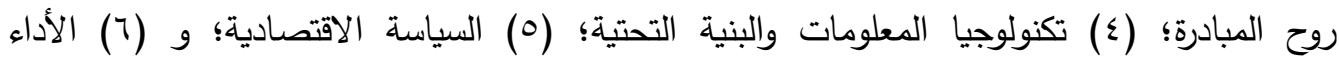
الاقتصادي.

INSEAD وقد تم إنشاء نظام تحليلى ثاني من قبل كلية إدارة الأعمال والمنظمه العالمية للملكية الفكرية business school and World Intellectual Property Organization (INSEAD \&

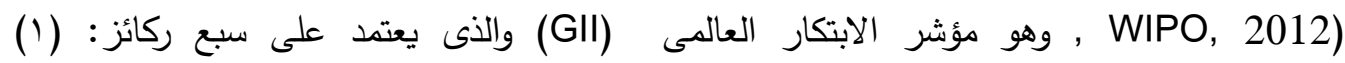

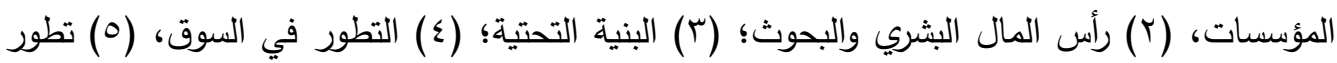

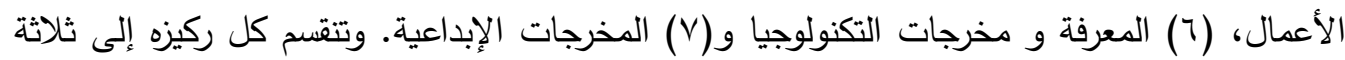
مؤشرات فرعية. ويتكون كل مؤشر فرعي من ثلاثة إلى ستة مؤشرات فردية. Boston Consulting Group مجوعة بوسطن الاستثارية والجمعية الوطنية الأمريكية للصناع and the American National Association of Manufacturers مؤشر يحمل نفس الاسم: مؤشر الابتكار العالمي , ولترتيب البلدان في هذه المنظومة الرابعه يتم قياس الخصائص الكميه لاقتصاد المعرفه لكل من مدخلات ومخرجات الابتكار • وتشمل مدخلات الابتكار: السياسة المالية والحكومية، وسياسة التعليم وبيئة الابتكار. وتشمل النواتج براءات الاختراع، ونقل التكنولوجيا، ونتائج البحث والتطوير الأخرى؛ أداء الأعمال، مثل إنتاجية العمل ومجموع عائدات المساهمين؛ تأثير الابتكار على الأعمال التجارية و الهجرة والنمو الاقتصادي. و قد تم نشر المؤشر في مارس 9. . . .

أما النظام الرابع فهو Global Innovation Quotient (ناتج الابتكار العالمي) الذي تتشره بلومبرغ كل عام. ويستتد هذا المؤشر على سبعة عوامل مع أوزان مختلفة: 
(1) البحث والتطوير كنسبة مئوية من الناتج المحلي الإجمالي، (r) الناتج المحلي الإجمالي للموظف، لكل ساعة عمل، (r) الثركات العامة ذات التقنية العالية (مثل الطيران والفضاء والدفاع، والتئه التكنولوجيا الحيوية، والأجهزة، والبرمجيات وأثباه الموصلات وبرامج الإنترنت وخدمات وشركات الطاقة المتجددة)

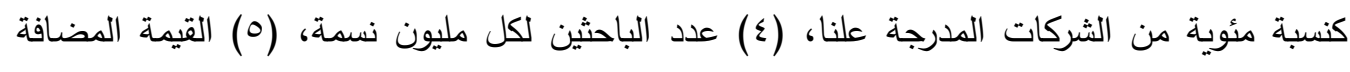

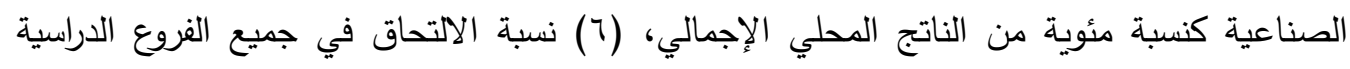

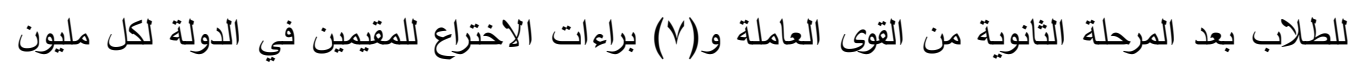

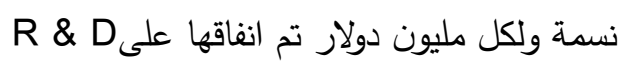
" إطار منظمة التعاون والتتمية OECD حيث ساهدت منظمة التعاون والتتمية إسهاما كبيرا في البحث عن اقتصاد قائم على المعرفة. وقد تطورت أعماله من تاريخ طويل من تطوير ونشر مؤشرات العلم

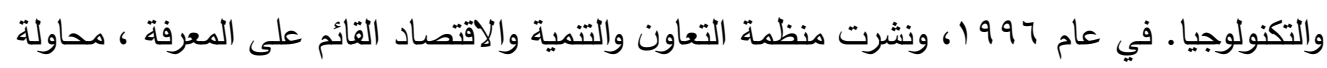

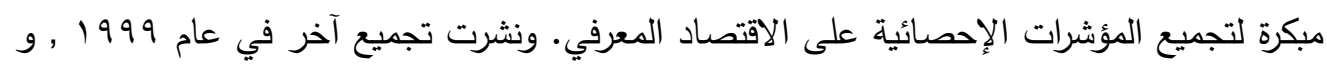

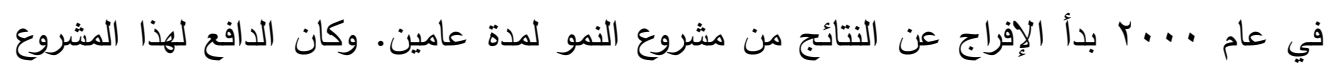
لاكتثاف الأسباب الكامنة وراء اختلاف النمو الاقتصادي في الدول الأعضاء خلال فترة التسعينات من القرن الماضى. وقد أنثأت منظمة التعاون والتتمية مؤشر مركب يسمى الاستثمار في المعرفة.

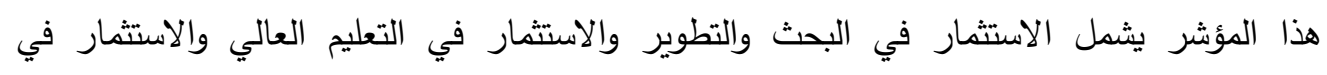
تكنولوجيا المعلومات والاتصالات والبرمجيات. على أساس هذا المؤشر تم تقسيم دول منظمة التعاون والتتمية إلى ثلاث مجموعات: الاقتصادات ذات الاستثمارات العالية فى المعرفة (التي تستثمر حوالي

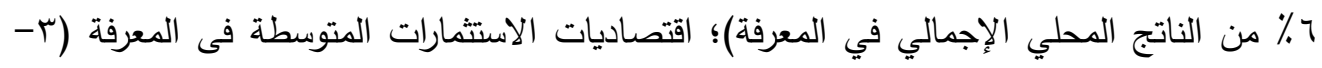

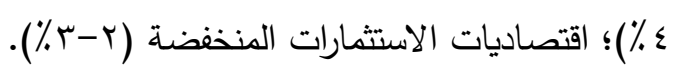

\section{: •}

لقد وضع إطار ال APEC كجزء من مشروع بتكليف اللجنة الاقتصادية APEC في منتصف

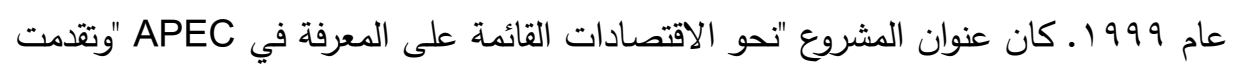
من قبل فرقة عمل أنشئت خصيصا لذلك KBE ، وان التي شملت أعضاء من أستراليا، كندا وكوريا. وكان الهدف من المشروع هو "توفير أساس تحليلي مفيد لتشجيع الاستخدام الفعال

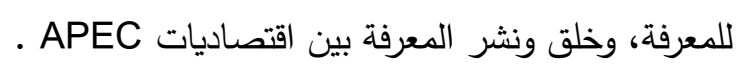

ويعتبر عدم وجود بيانات كافية هو العائق الرئيسي لقياس اقتصاد المعرفة. ووفقا لمنظمة التعاون والتتمية

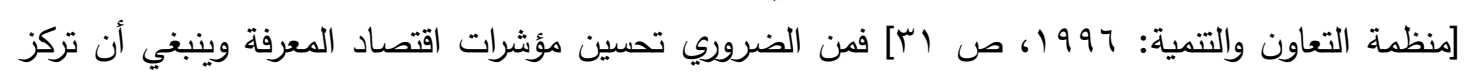
المؤشرات على: قياس مدخلات المعرفة؛ قياس مخزون وتدفقات المعرفة؛ قياس مخرجات المعرفة؛ قياس شبكات المعرفة وقياس المعرفة والتعلم.

(Knowledge Assessment Methodology) KAM أنثأها معهة البنك الدولي لمساعدة البلدان على تحديد التحديات والفرص التي تواجهها في محاولتها للتحول إلى الاقتصاد القائم على المعرفة. 
وتعتبر احد الطرق الممكنة لتقييم اقتصاديات المعرفة هي منهجية تقييم المعرفة، التي تمثل منهج تم إنشاؤه

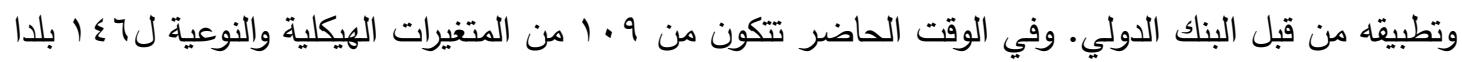
لقياس أدائها على أربعة دعائم لاقتصاد المعرفة (KE) : الحوافز الاقتصادية والنظام المؤسسي، التعليم والموارد البشرية، ونظام الابتكار، وتكنولوجيا المعلومات والاتصالات ICT. ويتم عرض الهن نتائج هذا التقييم من خلال مؤشرين أساسيين هما مؤشر المعرفة ومؤشر اقتصاد المعرفة ـ و يمكن أن تختلف قيم المؤشرات بين ( •-. ( ) ). ويعني ارتفاع المؤشر أن مستوى اقتصاد المعرفة مرتفع ايضاً.

$$
\text { - مؤشر المعرفة - مئ }
$$

يقيس مؤشر المعرفة قدرة بلد ما على إنتاج واعتماد ونشر المعرفة. وهو يثير إلى اجمالى تطوير المعرفة

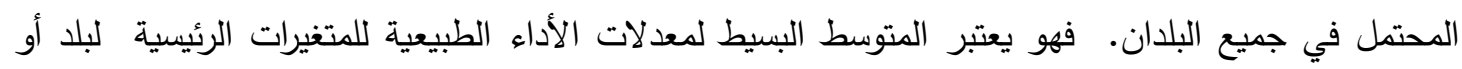

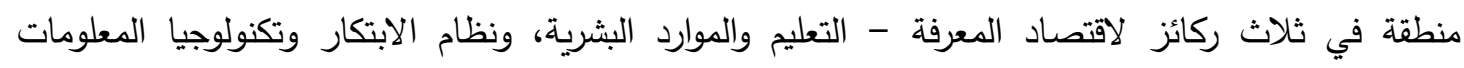
والاتصالات.

وتهيمن بلدان الاتحاد الأوروبي عموما على ترتيب اقتصاديات المعرفة. ومن وجهة نظر مؤشر المعرفة، فان

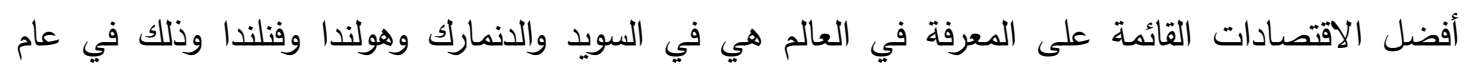

- مؤشر اقتصاد المعرفة

يقوم مؤشر اقتصاد المعرفة بتقييم ما إذا كانت البيئة تساعد على المعرفة التي يمكن استخدامها بفعالية للتمية الاقتصادية. وهو مؤشر كلي يمثل المستوى العام للتتمية للبلد أو المنطقة فى اتجاه اقتصاد المعادئ الدرفة. وهو يعتبر المتوسط البسيط لمعدلات الأداء الطبيعية لبلد أو منطقة اعتماداً على الركائز الأربع المتعلقة

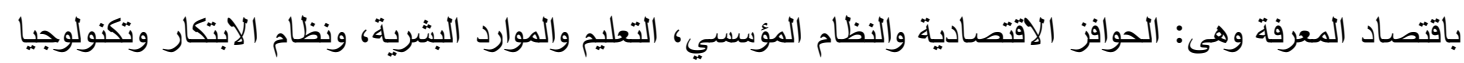
المعلومات والاتصالات [البنك الدولي : .... بـ]. 


\section{شكل رقم (1)}

\section{مئشرات المعرفة}

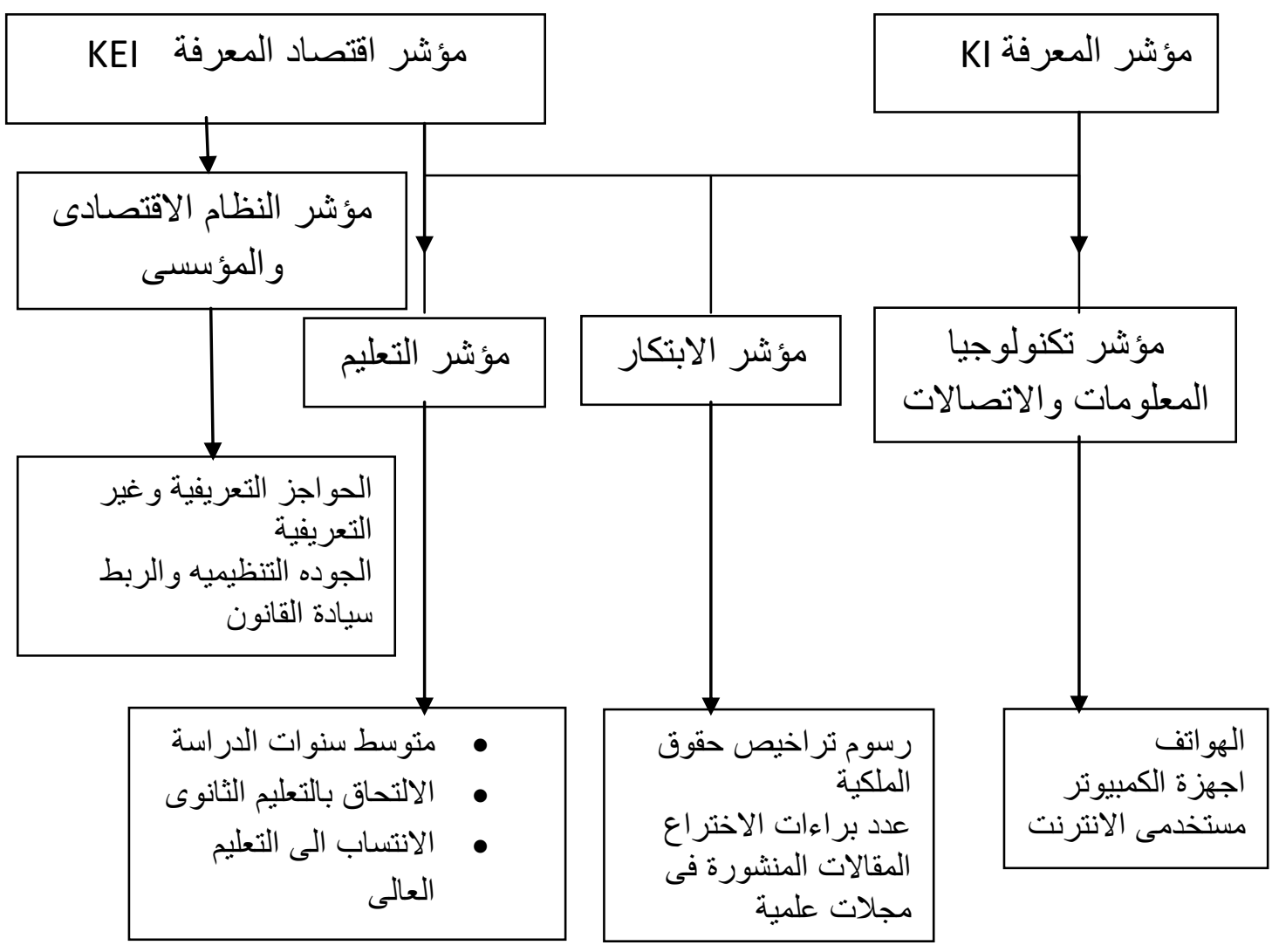

KEI المصدر : البنك الدولي, منهجية قياس اقتصاد المعرفة

ويتكون التقييم وفقاً لاطار البنك الدولى من أربعة ركائز ركما يتضح في الثكل السابق, كل واحدة تتكون من عدد

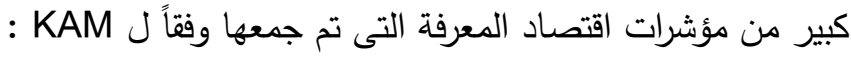

(1) الحافز الاقتصادى والنظام المؤسسى •

• الحواجز التعريفية وغير التعريفية.

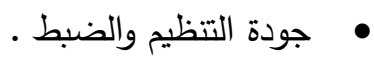

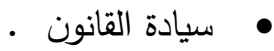

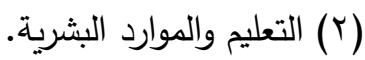

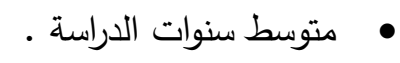

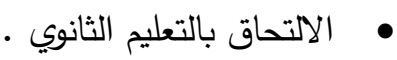

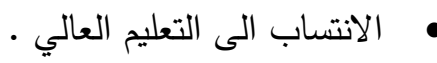

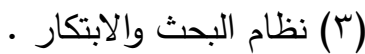

رسوم التراخيص وحقوق الملكية المدفوعة والمقبوضة .

عدد براءات الاختراع الممنوحة من قبل مكتب براءات الاختراع والعلامات التجارية الأمريكي . المقالات المنشورة فى المجلات العلمية والتقنية . 


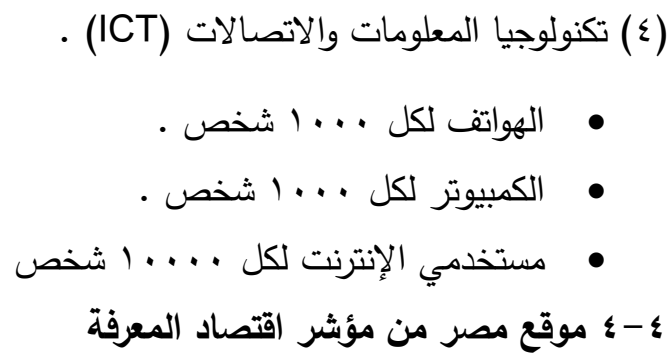

وبالنظر الى موقع مصر من مؤشر المعرفة في جدول رقم (Y) , فنجد أنها احتلت المركز Vومن بين بـ ا دولة

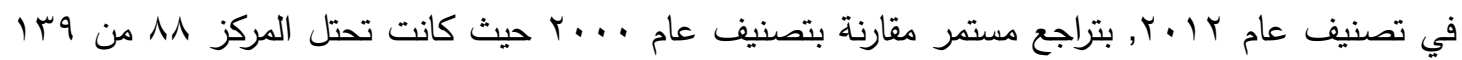
دولة ربينما كانت تحتل المركز اي من بين عبا دولة في عام 1990 وهو أول تصنيف يتم لهذا المؤشر , كما

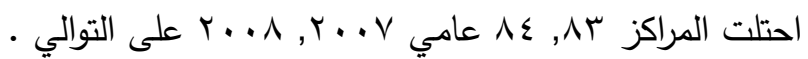
وذلك على الرغم من تقدم العديد من الدول العربية والدول النامية في مراكزها وفقاً لهذا المؤشر , فقد تقدمت

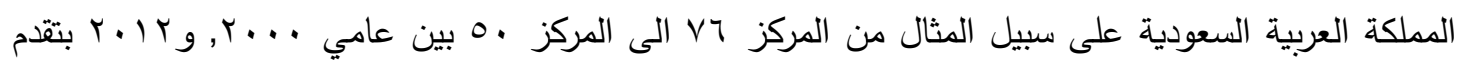
قدرة צr مركز , وهى تعتبر من اكثر الدول العربية والاسلامية تطوراً فى هذا المجال.

جدول رقم (r)

دليل البنك الدولي لاقتصاد المعرفة لمصر في فترات مختلفة

\begin{tabular}{|c|c|c|c|c|c|c|}
\hline \multicolumn{4}{|c|}{ مؤشرات فرعية } & \multirow[t]{2}{*}{ المؤشر } & \multirow[t]{2}{*}{ المركز } & \multirow[t]{2}{*}{ السنة } \\
\hline والاتنية & تعليم وموارد & بحث وابتكار & حوافز & & & \\
\hline- & - & - & - & $\varepsilon . \wedge\rceil$ & $\wedge 1$ & 1990 \\
\hline r.vV & $\varepsilon .77$ & r. & r. & $\varepsilon . r q$ & $\wedge \wedge$ & $r \ldots$ \\
\hline r.人9 & r.99 & $\varepsilon . r$ & r. r & r.q & س & $r \cdot . v$ \\
\hline r.7 & ס ט. & $\varepsilon .00$ & r.ov & ז. & $\Lambda \varepsilon$ & $r . . \Lambda$ \\
\hline م. r & $\varepsilon . \varepsilon$ & $\varepsilon .0$ & r. & $\varepsilon \ldots$ & س & $r . . q$ \\
\hline r.o & r.ov & $\varepsilon . \varepsilon r$ & $r$ & r.q & $q r$ & $r .1$. \\
\hline r.v & r.人 & $\varepsilon . Y_{I}$ & r.r & r.人ᄉ & ra & $r .11$ \\
\hline r. & ע.r. & 5.11 & $\varepsilon .0$ & r.V^ & $9 V$ & $r . \mid r$ \\
\hline
\end{tabular}

المصدر : بيانات مجمعة من مؤشرات قياس اقتصاد المعرفة (KEI), البنك الدولي. 


\section{ثانياً: البحث والتنمية والابتكار}

ان نقطة الانطلاق لخلق اقتصاد المعرفة التنافسي هو عمل مثل هذا النظام مع التعليم العالي الذي هو قادر على الاستجابة بمرونة لاحتياجات المناطق وأرباب العمل في وقت واحد واستخدام أحدث نتائج البحوث والتتمية. والعوامل الرئيسية لتحقيق النمو المستدام في المجتمع ما بعد الصناعي هي التطوير المنهجي للإِكانات البشرية (تعزيز القدرة للحصول على معرفة ومهارات جديدة, وسوق عمل مرن وقوى عاملة مرنة)، وتطوير إمكانات

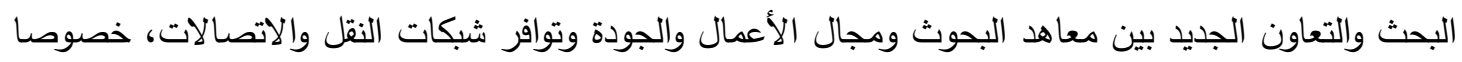
توافر التقنيات الحديثة.

\section{1 - تعريف البحث العلمي}

رغم انتشار البحث العلمي انتشارا واسعا إلا أن الباحثين لم يتفقوا على تعريف محدد له, ولعل ذلك يرجع إلى الى تعدد أساليب البحث (كالتجريب والتحليل والتنسير ...). وسوف نستعرض بعض التعريفات الأبسط والأشمل من وجهة نظر الباحثة.

هناك تعريف يتتاول البحث العلمي على أنه (( عملية فكرية منظمة يقوم بها شخص يسمى الباحث, من أجل تقصي الحقائق المتعلقة بمسألة أو مشكلة معينة تسمى موضوع البحث, باتباع طريقة علمية منظمة تسمى منهج البحث وذلك للوصول إلى حلول ملائمة للمشكلة أو إلى نتائج صالحة للتعميم على المشاكل المماثلة تسمى نتائج

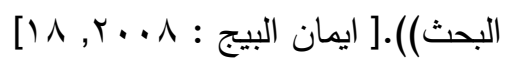
فهذا التعريف يركز على بيان مقومات البحث العلمي وهي: الباحث, وموضوع البحث, ومنهج البحث. البحث العلمي: (( هو مجموعة الجهود المنظمة التي يقوم بها الإنسان مستخدما الأسلوب العلمي وقواعد الطريقة

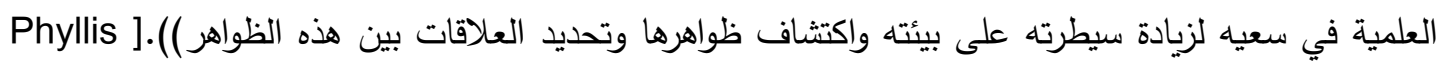

[Johnson : 2008, 8

يفيد هذا التعريف أن البحث العلمي مرتبط بأسلوب البحث وطريقته العلمية. وأن هدفه هو سيطرة الإنسان على البيئة عن طريق زيادة معارفه وتحسين قدرته على اكتشاف الحلول للمشاكل التي تواجهه.

بعد هذا العرض لتعريف البحث العلمي ومفرداته ,قد يبدو وجود خلل في ترجمة مصطلح Scientific "Research" "بّ" البحث العلمي" لأن ما يتبادر للذهن عند سماع كلمة العلم هو مجموعة من القوانين والعلاقات...بينما المراد هو إتباع منهج محدد أثناء البحث وعرض النتائج, لذلك حاول بعض المفكرين تفسير هذه الصفة" العلمي", على أن العلمي: كلمة منسوبة إلى العلم، و والعلم في طبيعته طريقة تفكير وطريقة بحث أكثر مما هو طائفة من القوانين الثابتة.

وأن إضافة صفة علمي إلى البحث......تعني فقط أن الباحث -أيا كان المجال الذي يبحث فيه - يستخدم المنهج العلمي أي الملاحظة والقياس, والاستدلال, والتجريب, بعيدا عن الحدس والاستبصار والوحي.

إلا أن البعض يرى أن استعمال كلمة "منهجي" في هذا السياق قد يكون أدق وأفضل من "علمي" ويؤيده أن كلمة

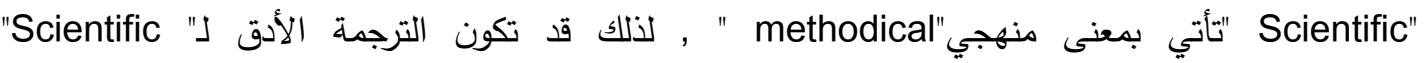
Research 


\section{r}

يشمل البحث العلمي والتطوير ثلاثة أنواع هي:

البحوث الأساسية: وهي تشمل عمليات البحث النظري الذي يتم مبدئياً من أجل اكتساب المعرفة حول ظاهرة أو

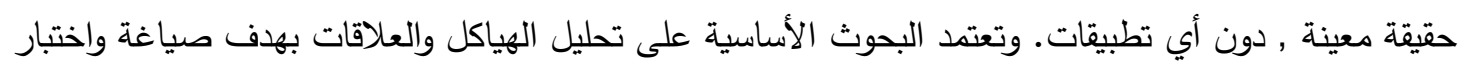

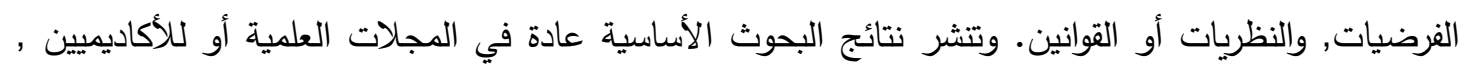
ولكنها عادة لا تباع.

البحوث التطبيقية: هي أيضاً عمليات بحث تتم لاكتساب معرفة جديدة, ولكنها تكون موجهاه نحو عملية محددة الهدف أو الغاية.

التطوير التجريبي: يعرف التطوير التجريبي على أنه عمليات التطوير التي تتم على أساس منتظم بالاعتماد على المعرفة التي توصلت اليها البحوث , ويتجه نحو انتاج مواد أو منتجات أو أجهزة جديدة أو تطوير ما سبق لتقيل

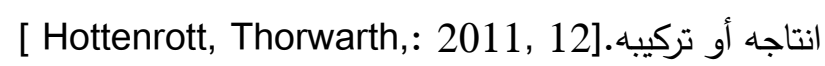

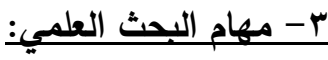

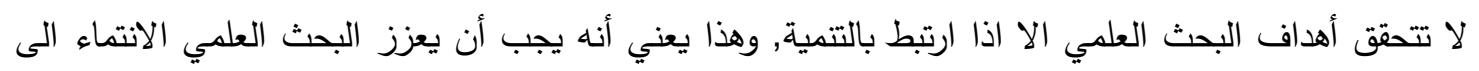

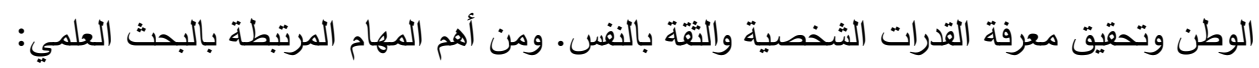

1- مهمة نشر المعرفة العلمية في المجتمع لتهيئة البيئة المناسبة للعلماء والباحثين للنهوض بالمجتمع, بالاضافة الى قدرة الباحثين على مواكبة البحوث العلمية العالمية ومواءمتها مع خصائص الدولة و المجتمع.

ץ- التتظيم الدقيق وتحديد الأولويات التي يحتاجها المجتمع وانعكاس ذلك على تطوير الصناعة, مع ربط مفهوم التتمية بمهام مؤسسات البحث العلمي ومراكز البحوث.

r- قيام مؤسسات البحث العلمي ببناء قواعد وشبكات ومراكز للمعلومات وتوافر البيانات والأرقام الدقيقة بهدف

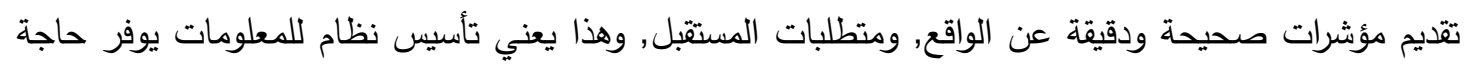
الباحثين من البيانات والمعلومات التي تساعد في الوصول الى نتائج دقيقة وفعالة وقادرة على حل المشكلات وتغيير الواقع الى الأفضل.

وعلى الرغم من أن الأبحاث النوعية تعتبر شرطا ضروريا لوضع البلاد نحو مجتمع المعرفة، فإنه ليس شرطا

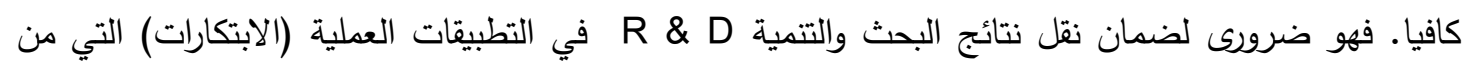
شأنها تعزيز نمو القدرة التتافسية للمؤسسات والمساهمة في التتمية المستدامة للبلد. الارتباط الوثيق بين البحوث

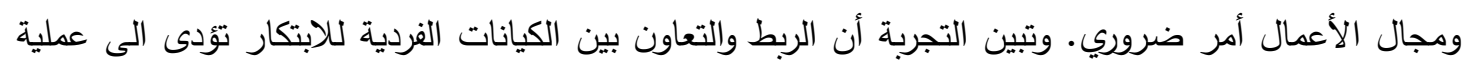
تسريع ملحوظ لإطلاق الابتكارات.

؛ - الابتكار باعتباره تحديا تنموياً ومعياراً لكفاءة الاقتصادات المعاصرة يعني الابتكار القدرة على خلق او البحث عن حلول جديدة قائمة على المعرفة ، وتكييفها مع ظروف كيانات

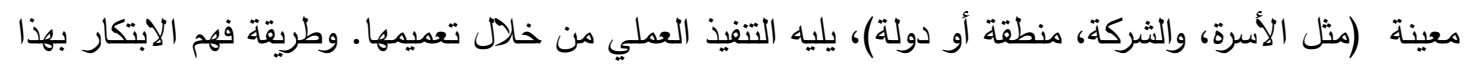

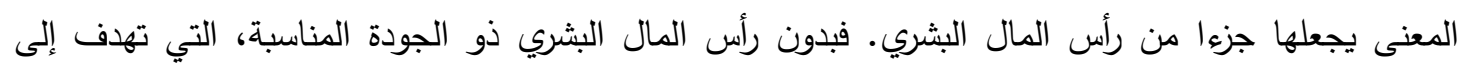


الإبداع, والابتكارات التي تعزز من الانجازات والطموحات، فإنه من الصعب تضييق فجوات التنمية الاقتصادية

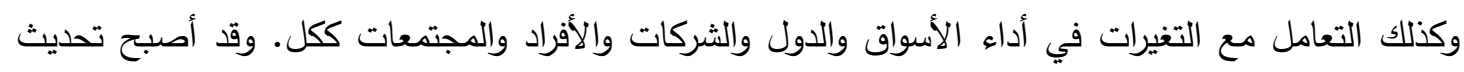
رأس المال البشري هو العامل الرئيسي لزيادة أهمية الابتكار و القبول به كتحدي رئيسي للتنمية ومعياراً لتقييم كفاءة النظم الاقتصادية.

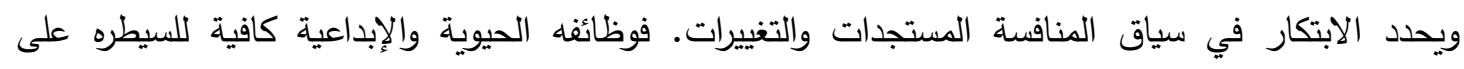
الاضطراب المتزايد فى البيئة. وفي هذه البيئة فان تكنولوجيا وادارة الابتكارات قد تعطي فرصة لتضييق فجوة التتمية. وتكثيف عمليات الابتكار يتطلب، تقديم آليات طبيعية (السوق) للاختيار و الخلق، فمثلاً نظرية التدمير الخلاق لشومبيتر لا تكن ممكنه دون منافسة. والتركيز على الابتكار كعامل يؤثر على المنافسة يعتمد على أسباب مختلفة. هذا يؤدى إلى الطابع المزدوج للابتكار كما لوحظ في مختلف النظم. فالابتكار كمورد مرتبط بالعوامل الأخرى, يوجد في أي منظمة (شركة) كتكلفة يتم تحديدها في البداية. ويمكن أيضا أن يكون موجود في المراحل الأولي كانعكاس للكفاءة التنظيمية

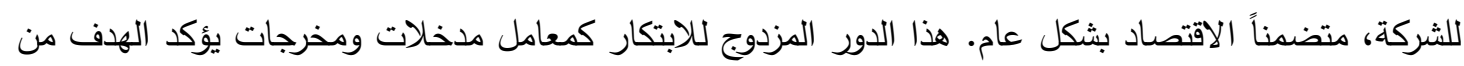

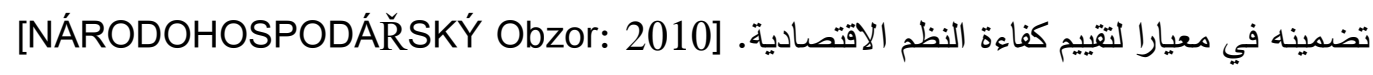
ان استخدام معايير الابتكار في خلق تصنيفات دولية للتنمية في بعض الدول يعتبر بمثابة المبرر العملي لإمكانية تطبيق الابتكار كمعيار لكفاءة (تحقيق الأهداف) وإنتاجية النظم الاقتصادية.

ويبدو التعريف التالى للابتكار ملائم لتحديات التنمية: الابتكار هو تتفيذ التغيير الذي يجلب بعض الفوائد

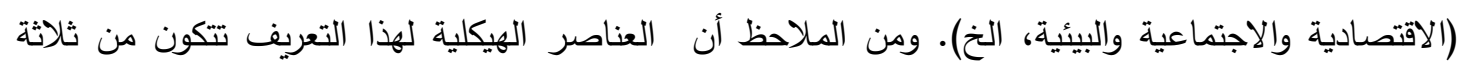
عناصر هي: التغيير، التنفيذ والفوائد التى تتعلق بجميع مناحي الحياة البشرية. يشير التغيير إلى حقيقة استبدال الدولة التقليدية بأخرى مختلفة. وهو ما يعني إدخال شيء جديد في أي مجال

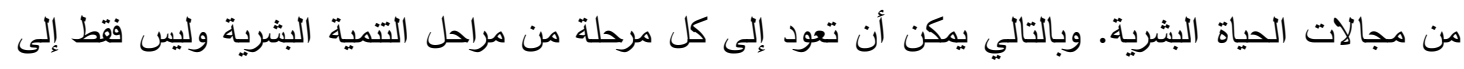

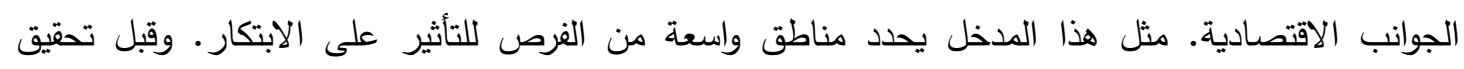

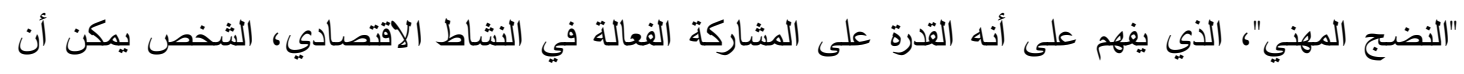
يمارس ذلك "الذين تدربوا على تنفيذ الابتكار "في مجالات نشاط حياته اليومية والتغيير لاينبغي أبداً أن يترك في مرحلة البداية, بل يجب أن يمتد الى ما بعد ذلك. التتفيذ، هو المكون الهيكليى للابتكار، وهو ضرورة لوجوده، وإن لم يكن مرضياً حتى الآن. وعوامل الضرورة

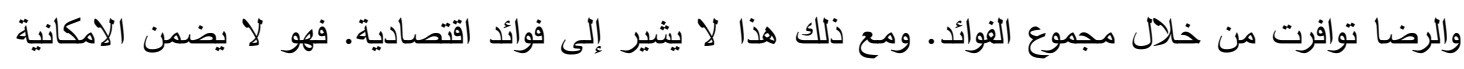
الكاملة لفهم نظرية الرفاهية الاجتماعية والفردية. والتركيز فقط على الآثار الاقتصادية، يشكل تعبيرا عن الاتجاه نحو هيمنة موقف كيان اقتصادي على الآخرين والتي يمكن أن تؤدي إلى عدم المساواة الاجتماعية.

ه- تقييم الابتكار

ويعتبر الابتكار هو أحد المؤشرات الهامه التى يقاس من خلالها قدرة الدولة على الانتقال الى اقتصاد المعرفة , فهو أحد الركائز الأربع المبنى عليها مؤشر اقتصاد المعرفة, بالاضافة الى البنية التحتية الاقتصادية و التعليم 
وتكنولوجيا المعلومات والاتصالات, وهو يقاس من خلال ثلاثة مؤشرات فرعية يبعاً لمؤشر اقتصاد المعرفة (KEl)

رسوم التراخيص وحقوق الملكية المدفوعة والمقبوضة .

عدد براءات الاختراع الممنوحة من قبل مكتب براءات الاختراع والعلامات التجارية الأمريكي .

$$
\text { المقالات المنشورة فى المجلات العلمية والتقنية . }
$$

وتعتبر هذه المؤشرات الفرعية هى المؤشرات التى يقاس من خلالها الابتكار كأحد ركائز اقتصاد المعرفة. وقد انشىء مؤخراً مؤشر خاص بالابتكار يسىى Global Innovation Index (GII) "مؤشر الابتكار العالمى", وقد برز مؤشر الابتكار العالمي (GII) بوصفه مؤشر ناجح حقا لترتيب الدول من حيث الابتكار في جميع أنحاء

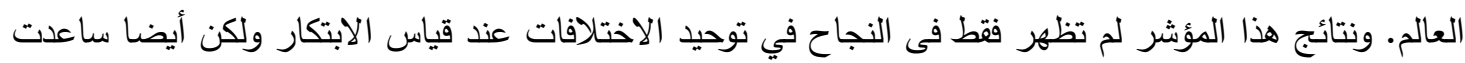
في بناء توافق بين دول العالم حول فعالية مثل هذه الدراسات لبناء السياسات المستقبلية.

، 'The Local Dynamics of Innovation' " وهناك تقرير سنوى يتتاول، " الديناميكيات المحلية للابتكار هام للغاية عندما نرى أنماط مختلفة للنمو الإقليمي فى العالم تأثرت بالجهات الفاعلة المحلية وتفاعلاتها. وهذا يعكس خصائص الأرض لكل أمة، وشعبها وثقافته. ودراسة هذه الديناميكيات المحلية مهم لأنه يمكن أن يوفر

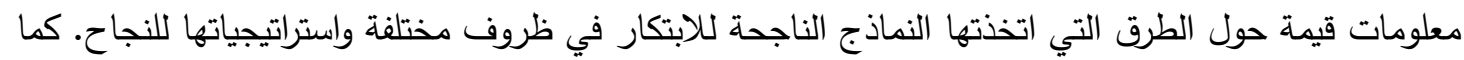
يمكن أن تساعد في تحديد كيف يمكن لهذه النماذج أن يتم نقلها عندما تكون الظروف منطابقة أو تعديلها عندما

$$
\text { تكون الظروف متثابهة. }
$$

واحد الجوانب الهامة لدراسة ديناميكيات الابتكار المحلي يرتبط بتتبع تحركات المعرفة الضمنية التي تسود في

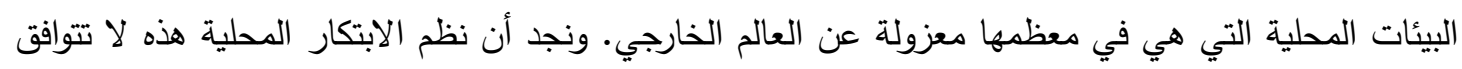

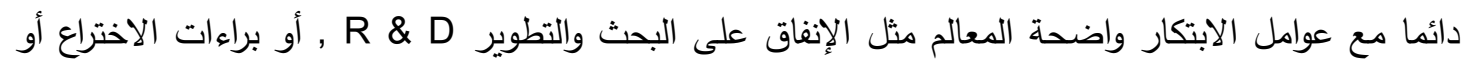

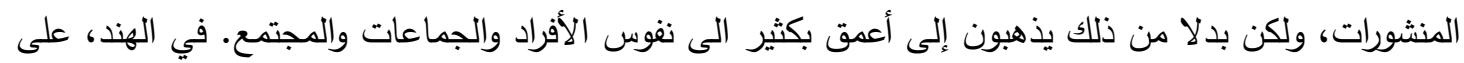

سبيل المثال، يمكننا أن نلاحظ كيف يعمل الابتكار المحلي و يتكيف في بيئة مقيدة بواسطة الموارد المتاحة. في المشهد اليوم الخاص بالعولمة، غالبا ما يرتبط الابتكار بالتقدم. فهو يمثل قدرة الدول علي التطور والتكيف مع الوجه المتغير للمنافسة وظروف السوق.

أحد الدوافع الهامة وراء إنثاء GII كان إدراك أن الابتكار أصبح أكثر عالمية، وأكثر توسع مما كان عليه من قبل. نتائج GII هذا العام وعلى مدى السنوات الماضية تقدم دليل على الطبيعة العالمية المتطورة للابتكار اليوم.

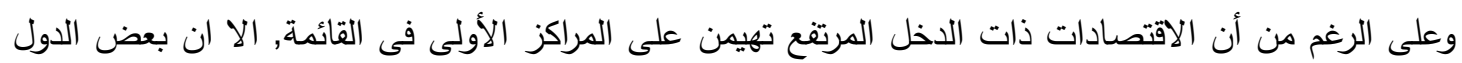
التى تلعب حديثاً فى هذا المجال زادت من قدرتها على الابتكار والمخرجات الناتجة عنده. ولقد شيدت المبادئ الأساسية لتصميم إطار GII، على أساس أحدث البحوث والبيانات لمقاييس ومؤشرات

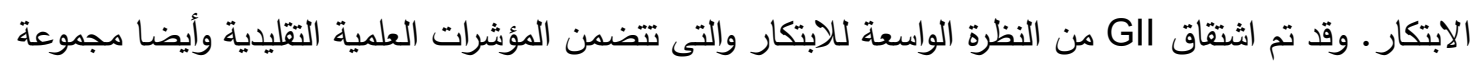
واسعة من المؤشرات الجديدة للمخرجات الإبداعية. 


\section{GII آلإطار المفاهيمي لمؤشر الابتكار العالمى}

ويوضح الثكل التالى أن GII يعتمد فى حسابة على مؤشرين فرعيين, المؤشر الفرعي لمدخلات الابتكار والمؤشر الفرعى للمخرجات ، وكل مؤشر مبنى على مجموعه من الركائز . وهناك أربعة معايير أو مؤشرات شاملة يتم حسابها:D Dutta, Lanvin : 2013]

1. المؤشر الفرعى لمدخلات الابتكار : هنالك خمسة ركائز المدخلات تصور عناصر الاقتصاد الوطني التى

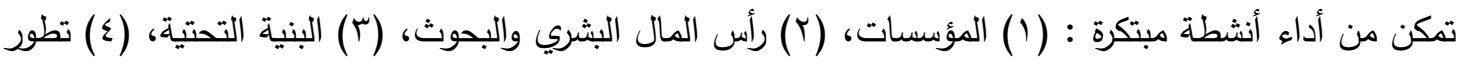

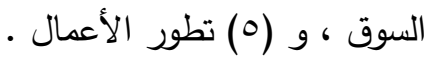

r. المؤشر الفرعى لمخرجات الابتكار : مخرجات الابتكار هي نتائج الأنشطة الابتكارية في الاقتصاد. وهناك

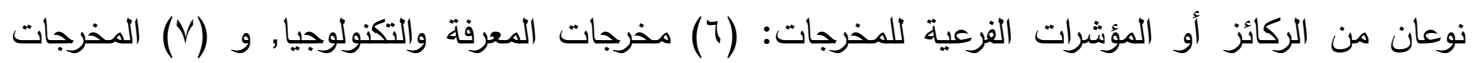
الإبداعية.

r. النتيجة الإجمالية ل GII هي المتوسط البسيط للمؤشرات الفرعية للمدخلات و المخرجات. ع. معدل كفاءة الابتكار هو ناتج قسمة المؤشر الفرعى للمخرجات على المؤشر الفرعى للمدخلات ـ وهذا يظهر مقدار مخرجات الابتكار لبلد معين والذى يتم الحصول عليه من مدخلاته. وينقسم كل مؤشر فرعى (ركيزة) إلى ثلاثة الركائز الفرعية وكل ركيزه تتألف من مؤشرات فردية، ليصبح المجموع ^^ مؤشر تستخدم لقياس الابتكار لكل بلد. 


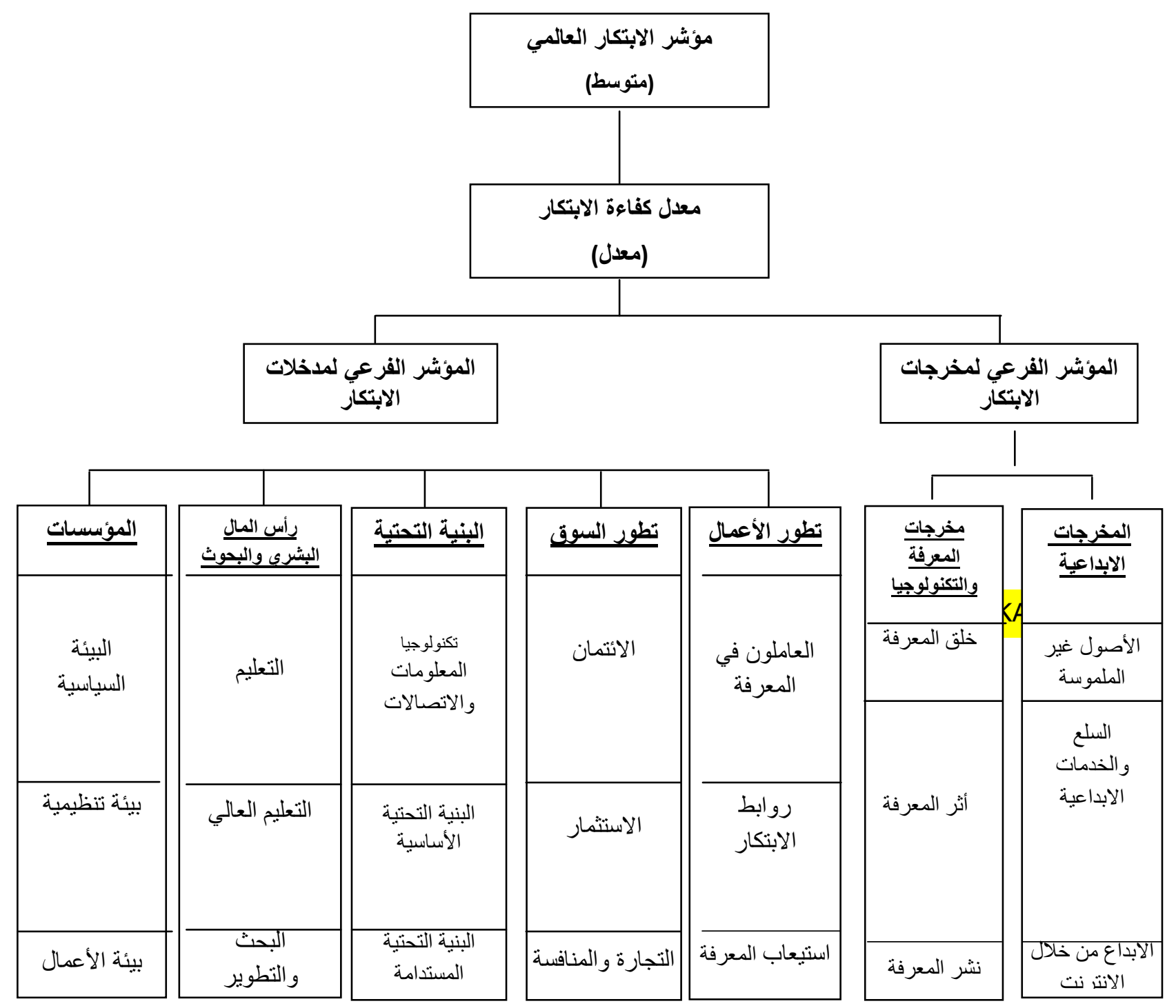

المصدر: 2013 The Global Innovation Index 


\section{ثالثاً: واقع البحث والتنمية والابتكار في مصر}

وتسهم البحوث العلمية ومراكز الدراسات في تطوير البناء التعليمي وربطه بالحياة الاقتصادية واحتياجات التتمية وتقديم أفكار تربوية , ولذلك فان مراكز البحوث والدراسات ترتبط بالانسان الذي هو وسيلة تحقيق التتمية. ولذلك ولك

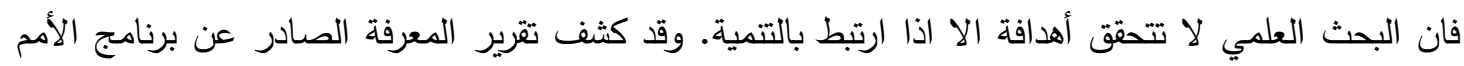
المتحدة للتمية عام 9 ج . r عن تدني المردود العلمي في مصر ومعظم دول العالم العربي حيث كانت أبرز

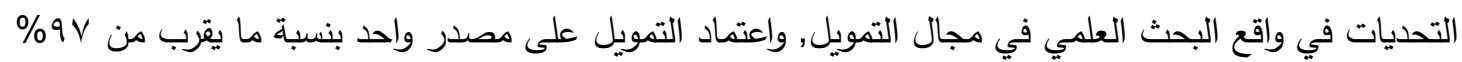

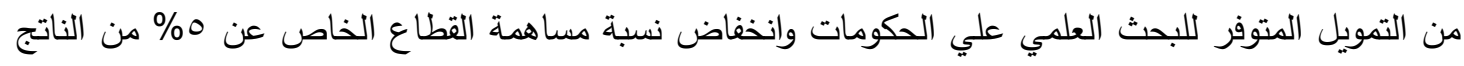
المحلي الاجمالي, مع وجود عجز واضح في القدرة على استقطاب تمويل القطاع الخاص والمؤسسات الخارجية.

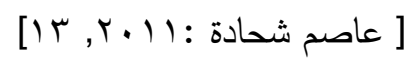

\section{1 - منظومة العلوم والتكنولوحيا في مصر}

تتكون منظومة العلوم والتكنولوجيا في الأساس من مجموعة من المؤسسات الادارية والبحثية التي تعمل تحت

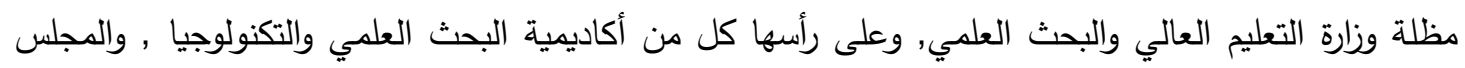
الأعلى للمراكز والمعاهد البحثية, وصندوق الاستثارات , وتتولى هذه المؤسسات عملية ادارة وتتظيم العلوم والتكنولوجيا في مصر , الى جانب القاعدة العلمية البحثية وما تحويه من مراكز ومؤسسات بحثية هامة.

\section{وزارة البحث العلمي}

و تقوم باعداد وتطوير ومتابعة الاستراتيجية القومية والخطط التتفيذية للبحوث العلمية للموافقة عليها من قبل المجلس الأعلى للعلوم والتكنولوجيا. أكاديمية البحث العلمي والتكنولوجيا تعمل على تطوير العلوم والتكنولوجيا في مصر , من خلال توظيف الطاقات العلمية والتكنولوجية بشكل فعال لخدمة التتمية من خلال عدد من المجالس النوعية والتي يبلغ عددها نحو ع أ مجلس من أمثلتها مجلس العلوم الطبية والتغذية ومجلس العلوم الاقتصادية والادارية, ومجلس العلوم الاجتماعية والانسانية والسكان وغيره.

$$
\text { المجلس الأعلى لمراكز البحوث }
$$

حيث تتركز رسالة هذا المجلس في تتسيق وتعظيم أداء مراكز ومعاهد البحوث, وتعزيز التجانس والتكامل فيما بينها, بما يساهم في تحقيق أهداف التتمية على المستوى القومي. صندوق الاستشارات يمثل آلية للتعاون بين مؤسسات العلوم والتكنولوجيا والجامعات والجهات الانتاجية. المؤسسات والمراكز البحثية

تتسم القاعدة العلمية في مصر بالتتوع والاتساع حيث تضم عدداً كبيراً من المؤسسات والمراكز البحثية التي تعمل في كثير من المجالات والقضايا البحثية المختلفة, مثل قضايا المياه والزراعة والطاقة والصناعة والتتمية التكنولوجية والبحوث الطبية. 


\section{المجلس الأعلى للعلوم وإلتكنولوجيا}

يختص هذا المجلس بالتخطيط الاستراتيجي لاستخدام البحث العلمي في التتمية, ووضع الرؤى المستقلية والمهام

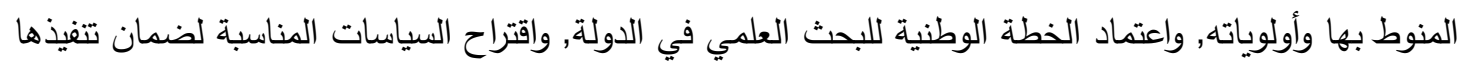
وتحقيق أهدافها.

صندوق العلوم وإلتنمية التكنولوجية يهدف الى تمويل الأنشطة العلمية والتكنولوجية وتطوير القدرة الابتكارية وكذلك التقييم المستمر لنظم العلوم والتكنولوجيا, الى جانب العمل على ايجاد آليات مناسبة ومرنة لتمويل منظومة العلوم والتكنولوجيا, بما يضمن التهن

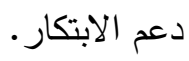

أعداد المراكز البحثية العلمية والجامعية في بعض المجالات عام I1 +.

\begin{tabular}{|c|c|}
\hline عدد المراكز & المجال \\
\hline r. & الزراعة \\
\hline ro & الطب والعلوم الطبية \\
\hline $1 \varepsilon$ & المياه \\
\hline $1 \leq$ & التعليم والثقافة \\
\hline 1. & العلوم الاجتماعية \\
\hline$\wedge$ & الطاقة \\
\hline 7 & الصناعة والتنمية التكنولوجية \\
\hline$\varepsilon$ & الثؤون الاجتماعية \\
\hline r & الاسكان \\
\hline r & تقنيات البيئة \\
\hline$r$ & تقنيات النقل والمواصلات \\
\hline 1 & الثباب والرياضة \\
\hline 1 & التخطيط \\
\hline 1 & القوى العاملة \\
\hline$|r|$ & الاجمالي \\
\hline
\end{tabular}

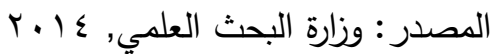

r - هيكل البحث والتنمية والابتكار في مصر

من المعروف أن نظام البحث والتتمية والابتكار يساهم مساهمة كبيرة في التتمية الاقتصادية الوطنية والرفاهية الاجتماعية .فالأمم التي تتمي أصولها المعرفية وتديرها بفعالية تحسن من أدائها الاقتصادي، وكذلك الشركات

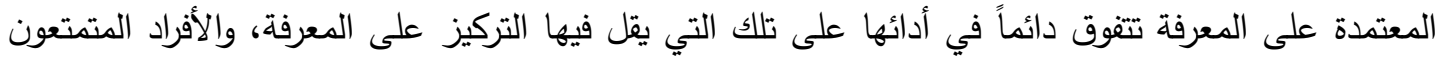
بحصيلة أكبر من المعرفة يحصلون عادةً على فرص عمل أفضل .وتثكل الاستثمارات في البحث والتتمية والابتكار، والتعليم والتدريب، وغير ذلك من الأصول غير المادية حجر الزاوية لاقتصاد المعرفة الحديث . 
ويشكل إصلاح نظام البحث والتتمية والابتكار في مصر عنصرا أساسيا من عناصر إصلاح قاعدة المعرفة

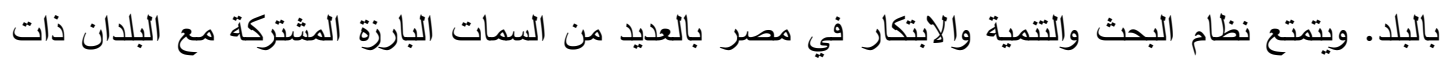
الاخل المتوسط الأدنى الأخرى في المنطقة وفي جميع أنحاء العالم والتي تتمثل في عدم وجود استراتيجية قومية

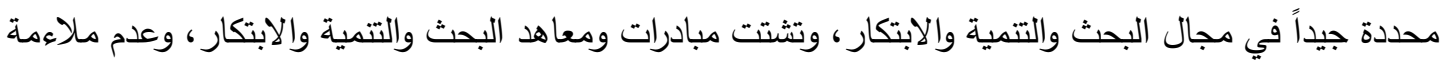
مستوى التمويل، وضعف القوة الإجمالية للبحث العلمي، وضعف إدارة البحث والتتمية والابتكار .

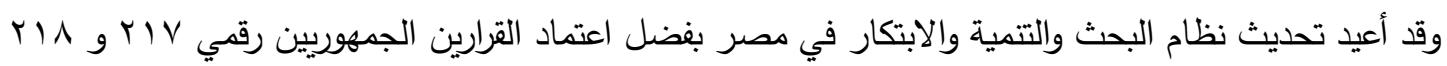
في يوليو V... Y بثأن إنثاء المجلس الأعلى للعلوم والتكنولوجيا، وصندوق العلوم والتتمية التكنولوجية على التوالي.

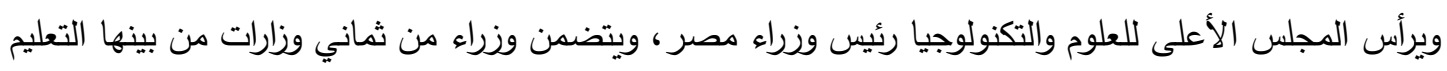

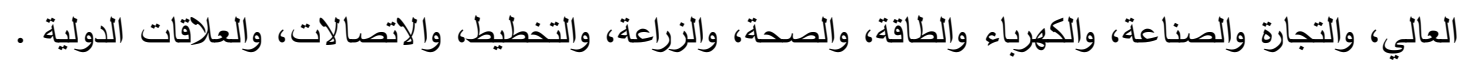

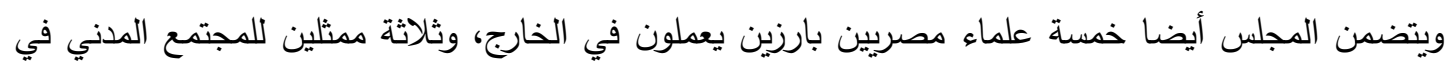

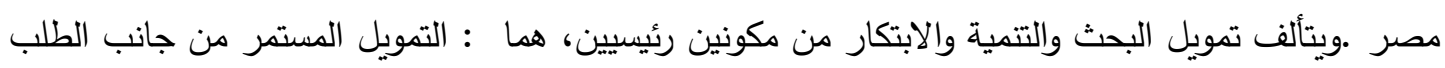
لنفقات تشغيل المؤسسات القائمة على مستوى مخفَّض من وزارة المالية، ) , (تمويل أكبر كثيرا لمشروعات البحث

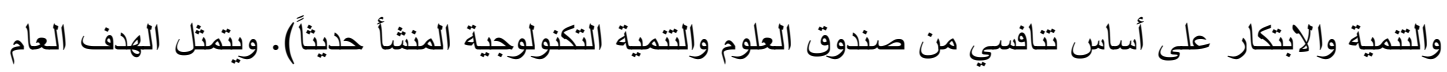
من إعادة الهيكلة المقترحة في زيادة الإنفاق على البحث والتتمية والابتكار من المستوى الذي كان عليه خلال

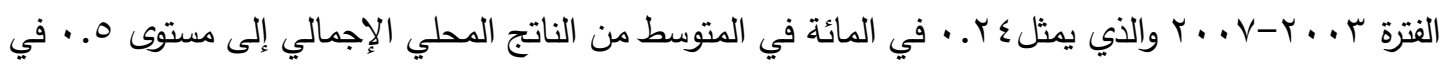

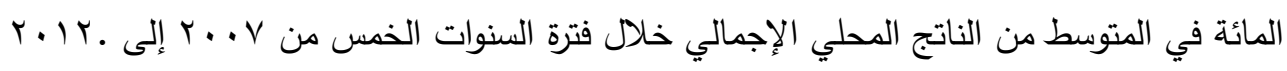

\section{r- تحديد الأولويات في البحث والتنمية والابتكار}

حتى منعطف القرن، كان لنظام البحث والتتمية والابتكار في مصر اثثان من أصحاب المصلحة :الأوساط البحثية المكونة من جميع المؤسسات البحثية الحكومية داخل الجامعات الحكومية وخارجها، والحكومة من خلال وزاراتها التي تمول هذه المؤسسات .وكان تركيز المجموعة الأولى ينصب بصفة رئيسية على ضمان التهان التمويل

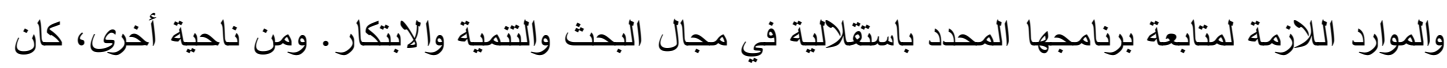

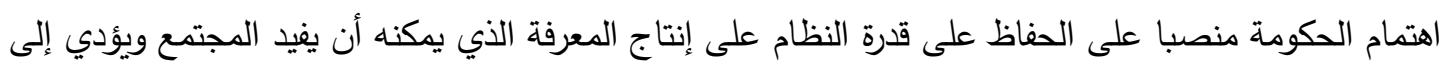

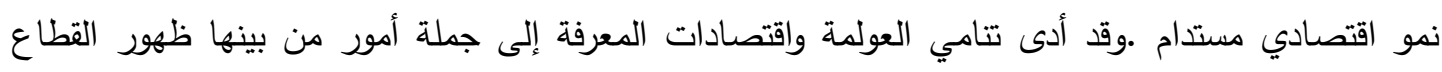

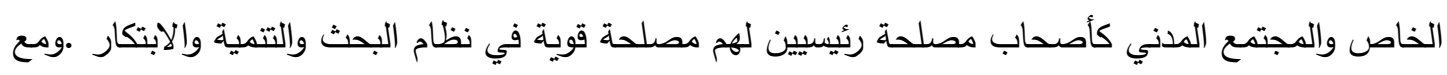

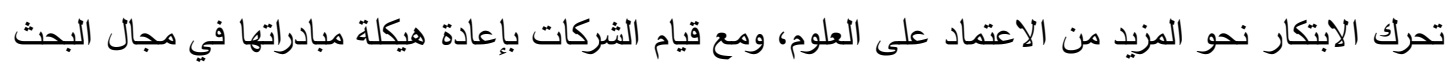

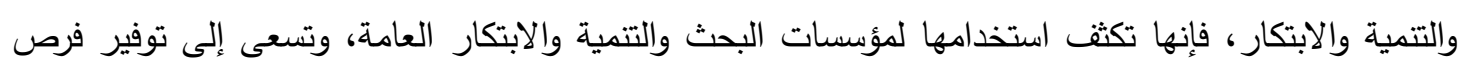
الوصول أمام أصحاب المهارات من الباحثين والمهندسين الثباب .وأي إصلاح لهيكل البحث والتتمية والابتكار وأي تمويل له ينبغي الآن أن يسترشد أيضا بمصالح القطاع الخاص ومنظمات البجتمع المدني. يقدم التمويل لنظام البحث والتتمية والابتكار في مصر في المقام الأول من وزارة المالية استنادا إلى وثائق

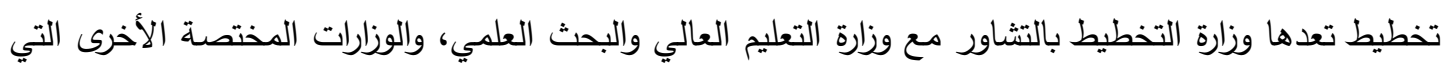

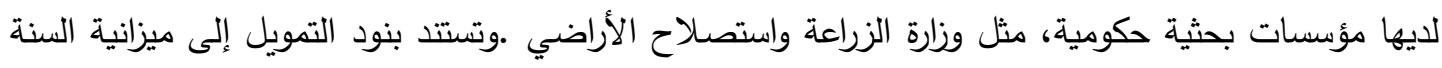

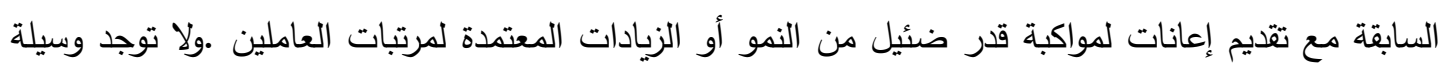


منهجية لتقييم مستوى الاستثمار اللازم لتطوير البنية الأساسية وشراء التكنولوجيات أو المعدات أو المستلزمات أو

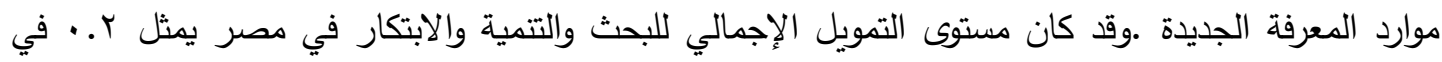
المائة من الناتج المحلي الإجمالي، وهو مستوى أدنى من معايير منظمة التعاون والتتمية في الميدان

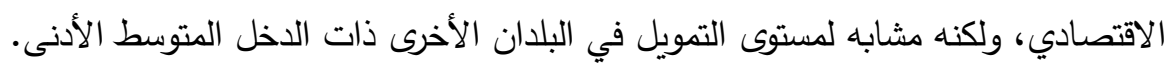

ويعين عادةً الباحثون في المؤسسات البحثية الحكومية بعد إتمام الدرجة العلمية الأولى في العلوم أو الهندسة أو

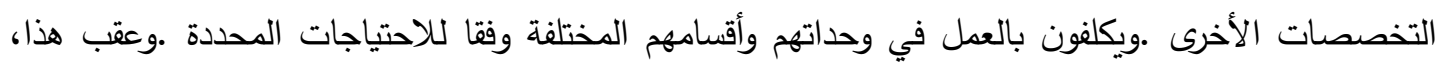

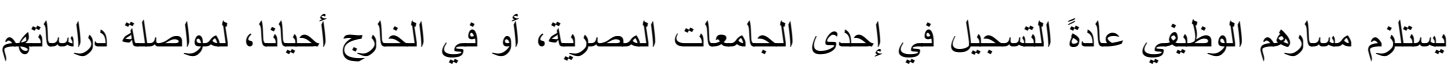
العليا في مجالات ذات الصلة بأعمالهم في المؤسسة البحثية الحكومية لنيل درجتي الماجستير أو الدكتوراه . وكثيرا ما يتم الإشراف عليهم إشرافا مشتركا بواسطة عضو هيئة تدريس بالجامعة وأحد كبار العاملين في

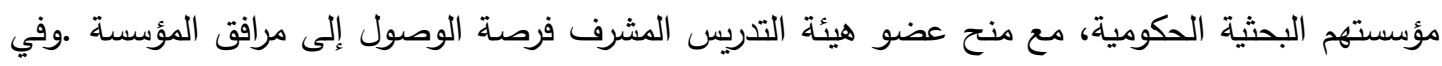

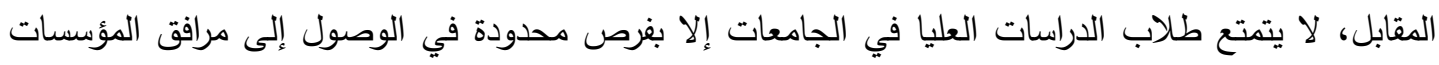

البحثية الحكومية.

ع - التحديات الأساسية التي تواجه المعرفة والابتكار والبحث العلمي في مصر

لقد أوضحت الدراسات التي أجريت في هذا المجال أن هناك نقص فى وجود استراتيجية عامة للابتكار التي

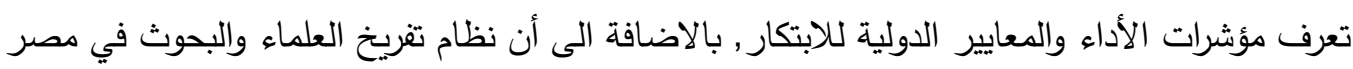
لا يزال قيد التطوير •

التعاون بين البحوث والصناعة محدودة للغاية بسبب انعدام الثقة المتبادلة وانعدام الحوافز. لا يمكن الحصول على قروض للبحوث العلمية الا من خلال الأنثطة العلمية الكلاسيكية أكثر من الأنشطة العلمية التى لها علاقة بالصناعة. هناك عدد محدود من المؤسسات العلمية المتخصصة مثل (مدينة البحوث العلمية والتقنية، الأقطاب التكنولوجية, القرية الذكية) وهكذا.

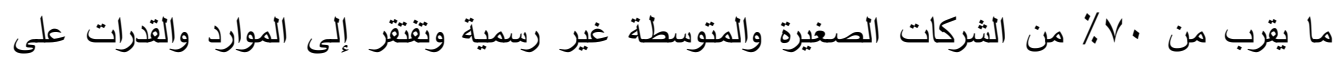
الابتكار أو حتى التعامل مع الثركات الكبيرة.

تقريبا كل رؤوس الأموال VCs) Venture Capitals التى تستثر في مشاريع عالية المخاطر في مراحل مبكرة، لا تتورط فى هذه المشروعات حتى يروا نموذج أولى لإثبات المفهوم أو الفكرة. وكذلك هناك مشكلة فى عقلية معظم المسؤلين عن الإدارة العامة أن المال العام لا ينبغي أن يخصص للقطاع الخاص حتى وان كان سيعود فى النهاية بالنفع العام. نشر المعرفة لايزال سابق لأوانه نظرا لعدم وجود دورات التعليم والتدريب الكافية في ريادة الأعمال،

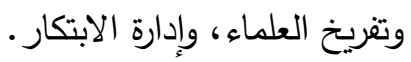
هجرة العقول، ما يقرب من هب٪ من طلبة الدكتوراه الذين يدرسون في الخارج لا يعودون إلى مصر . 
التدريب المهني والتعليم التقني غير الفعال ، انخفاض النسبة المئوية للطلاب الذين ينضمون لدراسة

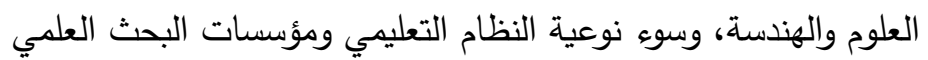

القطاع الصناعى لا يوجد لايه مشاركة حقيقية في طبيعة أو أهمية البحوث التي أجريت من قبل المجتمع مما يؤدى الى الانفصال بين البحوث والتعليم؛ وحاجة السوق.

انخفاض التعاون بين أصحاب المصلحة فى الابتكار . مع عدم وجود طلب للسوق على الابتكار، فضلا عن عدم وجود حوافز والأدوات العملية لتعزيز الابتكار (البيئة المميكنة). [ عدم وجود مؤشرات/ مقاييس للابتكار (سواء للبحوث أو الصناعة) لقياس الأداء ورصد التقدم المحرز

[Ahmed Saleh: 2013

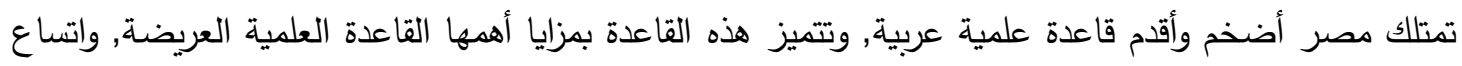

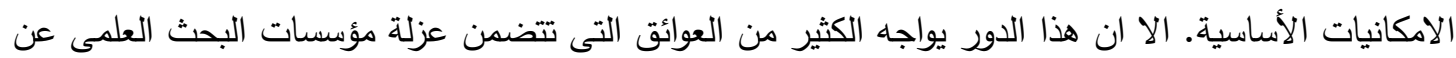

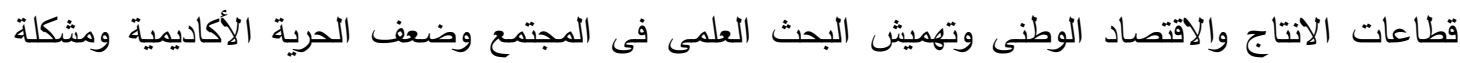

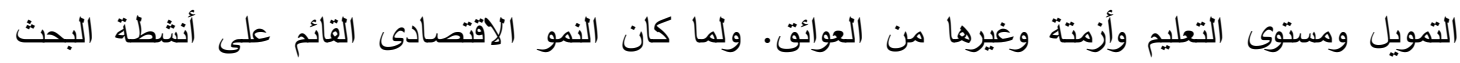

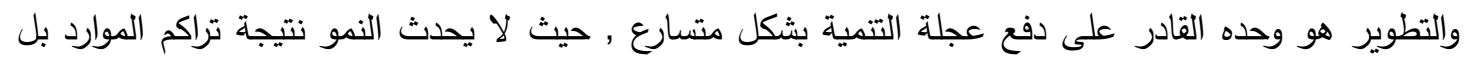
نتيجة القيمة المضافة فى العملية الانتاجية من خلال تحسينها, فان البحث فى عوائق البحث العلمى فى الحقل

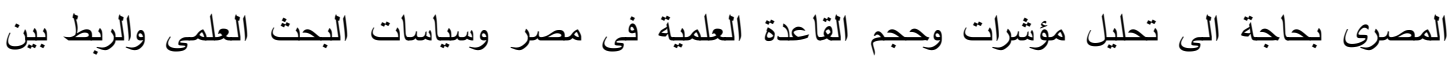

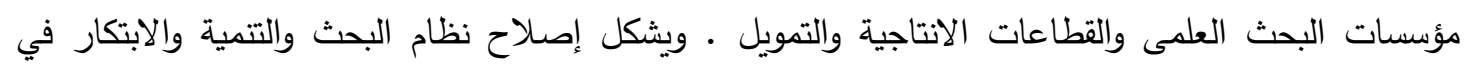

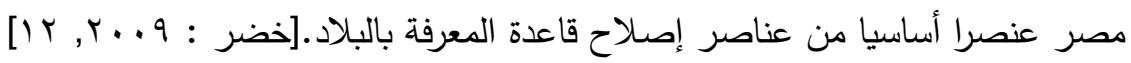
وسوف نستعرض في هذا الجزء كل من مدخلات ومخرجات البحث والتمية والابتكار في مصر لتحديد نقاط

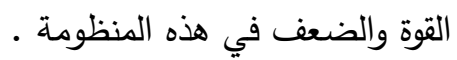
ه- مدخلات البحث والتنمية والاتكار في مصر في تعتبر أهم مدخلات البحث والتتمية والابتكار هي الموارد البشرية والموارد المادية, وذلك وفقاً للعديد من الدراسات

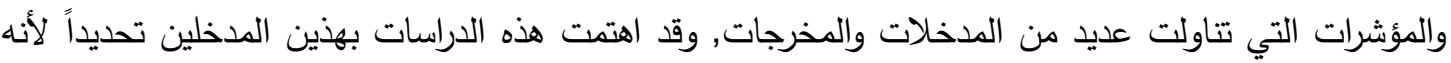
قد ثبت أنهما أكثر الدذخلات تأثيراً على عملية الابتكار والبحث العلمي.

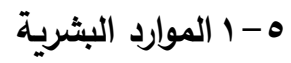

تعتبر الموارد البشرية هي أهم عناصر البحث العلمي, اذ لابد من توفر الكفاءات القادرة على الأداء والعطاء المتميز في هذا المجال.

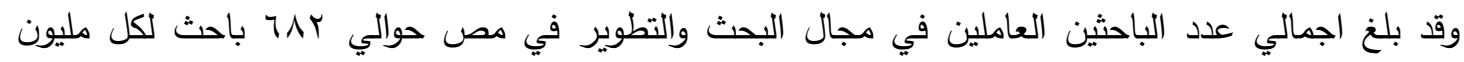

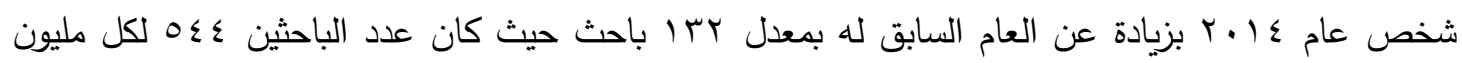

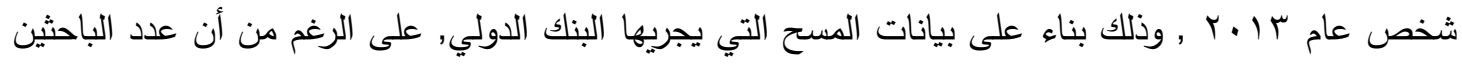

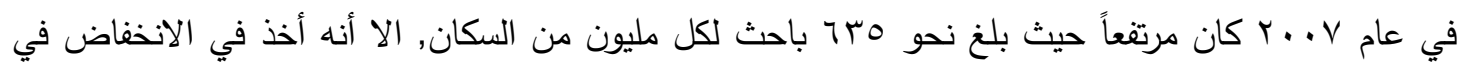

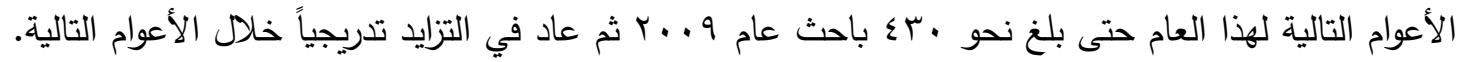


ويبدو أن هذه الزيادة تزامنت مع المبادرات التي قامت بها الدولة والاتفاقيات الدولية التي من شأنها دعم البحث العلمي والباحثين وتقديم الدعم المادي لهم من خلال المنح الداخلية والخارجية. وبالاضافة الى هؤلاء الباحثين هناك عدد من الفنيين العاملين في هذا المجال والذين بلغ عددهم حوالي هـب, r rVT

وقد بلغ نصيب العالم من الباحثين حوالي الف باحث لكل مليون شخص في فترة ما قبل عام • ـ ب وزاد هذا

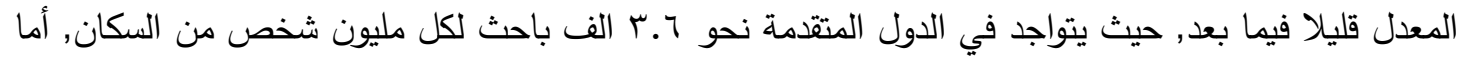

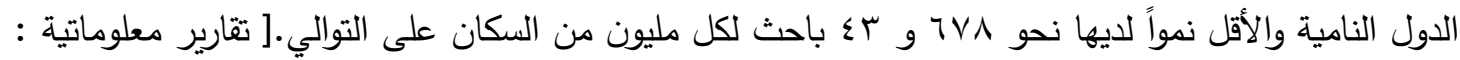

عدد الباحثون العاملون في مجال البحث والتطوير في مصر

(لكل مليون شخص )

\begin{tabular}{|c|c|}
\hline عدد الباحثون & السنة \\
\hline 1.. & $r \ldots v$ \\
\hline$\varepsilon \varepsilon Y, Y V$ & $r \ldots r$ \\
\hline$\varepsilon r V . . T$ & $r \ldots q$ \\
\hline$\sum 97 . V T$ & $r .1$. \\
\hline$\sum 97.1 \%$ & $r+11$ \\
\hline orl.V & $r+1 r$ \\
\hline $0 \leqslant r . \wedge q$ & $r \cdot 1 r$ \\
\hline 711.71 & $r+1 \varepsilon$ \\
\hline $7 \vee 9.11$ & $r .10$ \\
\hline
\end{tabular}

المصدر : بيانات تم جمعها من بيانات البنك الدولي سنوات مختلفة 
الفنيون العاملون في مجال البحث والتطوير في مصر

(لكل مليون شخص )

\begin{tabular}{|c|c|}
\hline عدد الفنيون & السنة \\
\hline $1 \times 0.19$ & $r \ldots v$ \\
\hline r)..T. & $r \ldots \wedge$ \\
\hline$r \leqslant 0 . V V$ & $r \ldots q$ \\
\hline ror.. r & $r \cdot 1$. \\
\hline YTr..V & $r .11$ \\
\hline r.9.0r & $r .1 r$ \\
\hline rVO.rT & $r \cdot 1 r$ \\
\hline ros.9 & $r+1 \varepsilon$ \\
\hline
\end{tabular}

المصدر : بيانات تم جمعها من بيانات البنك الدولي سنوات مختلفة 


\section{أعداد الباحثين فى مجال البحث العلمى والتطوير لكل

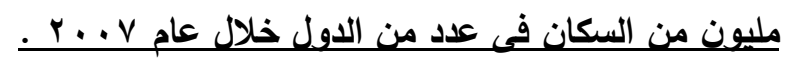

(باحث لككل مليون من السكار, 2) (ب)

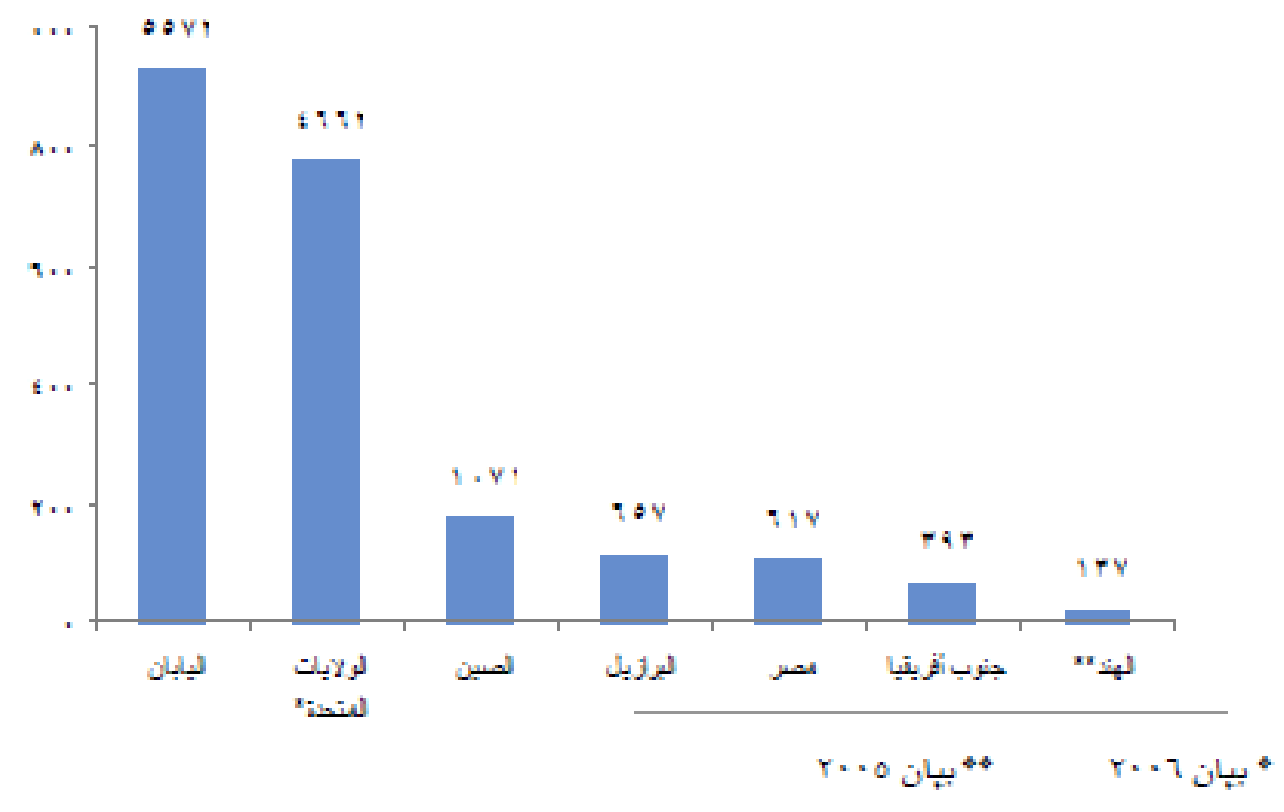

المصدر :

UNESCO Institute for Statistics, Global Perespective on Research and Development, August 2011.

وقد أعلنت أكاديمية البحث العلمي، أن مؤشر البحث العلمى لشهر فبراير كثف أن إجمالى عدد الباحثين

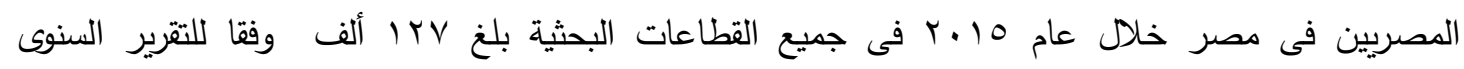

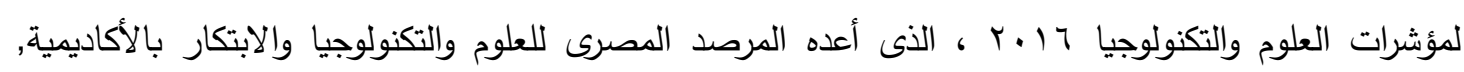

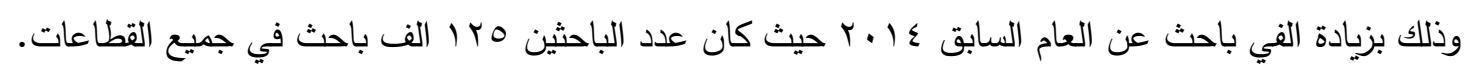

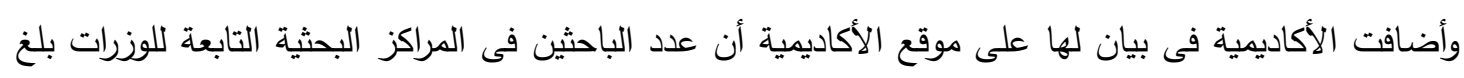

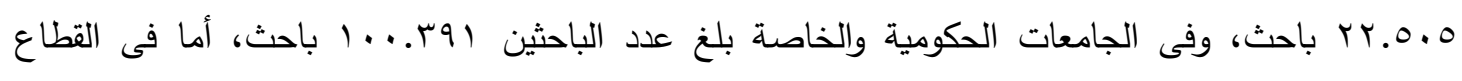

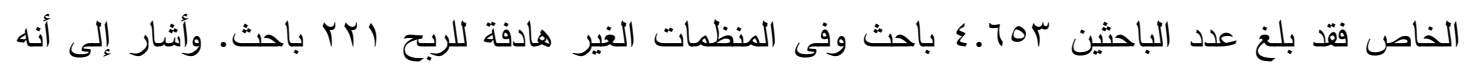

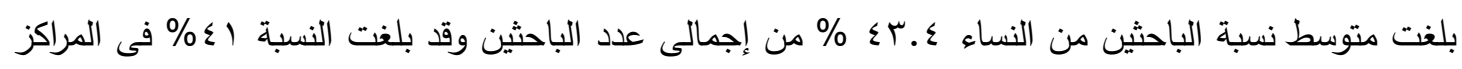

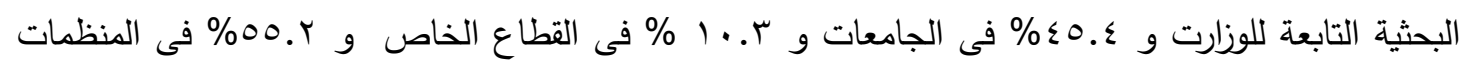
غير الهادفة للربح.

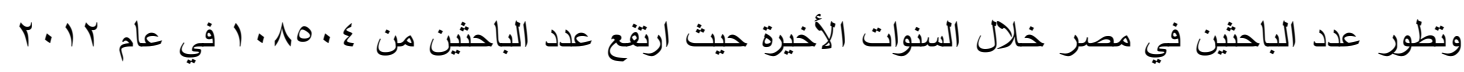

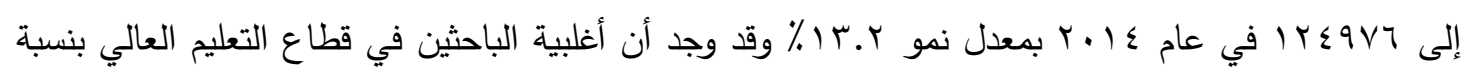

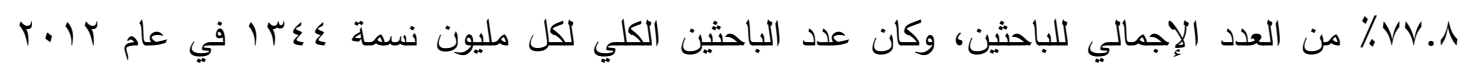

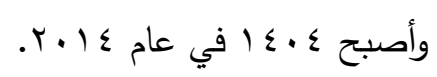




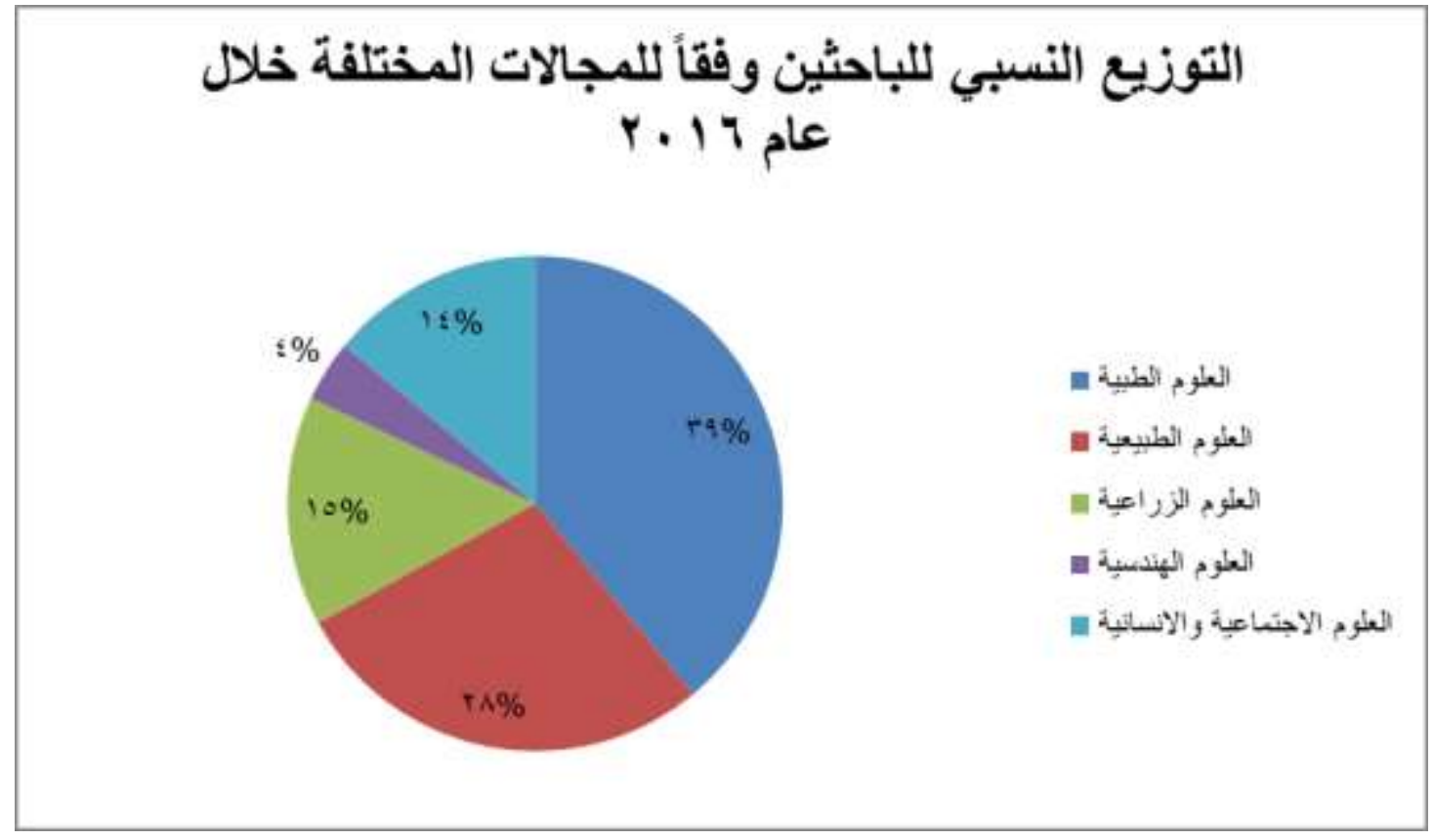

المصدر : تم جمع البيانات من تقرير مؤشر البحث العلمي, أكاديمية البحث العلمي ه- ب الموارد المالية المخصصه للبحث والتنمية والابتكار في مصر

نتتاول في هذا الجزء رصداً لحجم الموارد المالية المخصصة للبحث العلمي وهيكل تمويله , وحجم الانفاق على البحث العلمي وتوزيعاته المختلفة.

لقد بلغ الانفاق على البحث والتطوير والابتكار رقما قياسيا في عام ع ا.ب حيث بلغ V. ا تربليون دولار تقريبا.

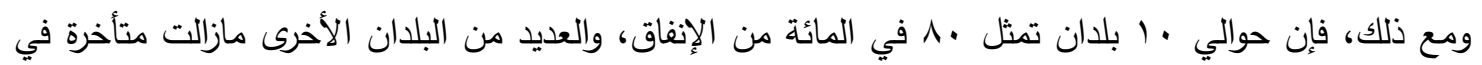

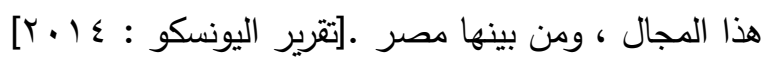

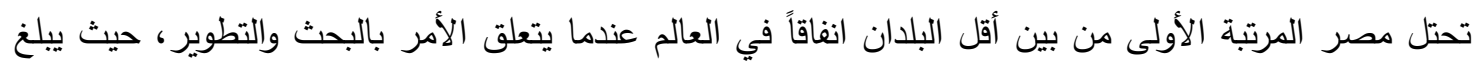
الإنفاق الإجمالي أقل مما يتطلبه الدستور المصري وأقل بكثير من أهداف التتمية المستدامة، وفقا للأرقام الواردة

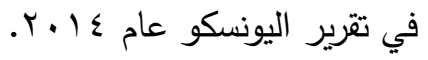
وقد أوضح التقرير أن إجمالي الإنفاق على البحث والتطوير في مصر بلغ ع.7 مليون دولار عام ع ا. ك، وهو ما يمثل V. • في المائة فقط من إجمالي الناتج المحلي للبلاد، وهو أقل من الهدف المحدد في الدستور والبالغ الفي في المائة

وقد رصد مؤشر البحث العلمى أن Yr. . \% هى نسبة الإنفاق على البحث والتطوير من إجمالى الدخل القومى

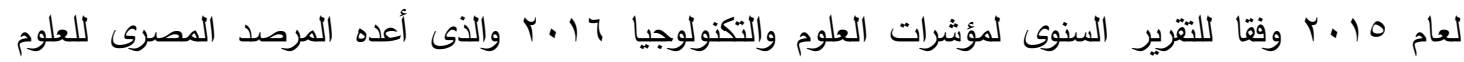

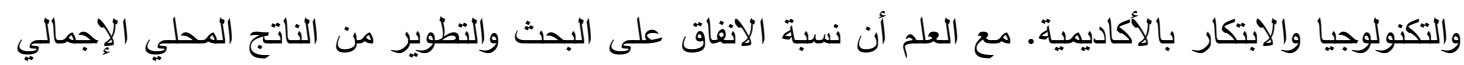

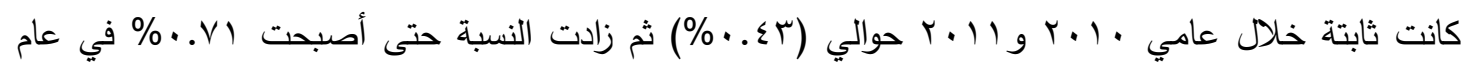


وتثمل تلك النسبة الإنفاق على البحث والتطوير فى المراكز البحثية التابعة للوزارات وقطاع التعليم العالى (الجامعات) والقطاع الخاص إلى جانب المؤسسات غير الهادفة للربح، وقد تم حساب النسبة وفقا للمعايير

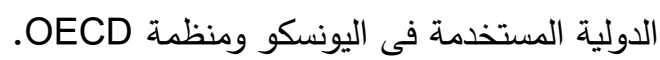
ويعتبر مؤشر "الثهر" هو مؤشر للعلوم والتكنولوجيا، يصدره شهريا المرصد المصرى للعلوم والتكنولوجيا والابتكار بأكاديمية البحث العلمى والتكنولوجيا. وكانت أكاديمية البحث العلمى والتكنولوجيا، قد قامت بإنشاء المرصد المصرى للعلوم والتكنولوجيا والابتكار فى فبراير ـ ا ـ Y، كإضافة لجهودها الرامية لتعزيز تتمية الاقتصاد القائم على المعرفة، ويهدف إلى مساعدة صانعى

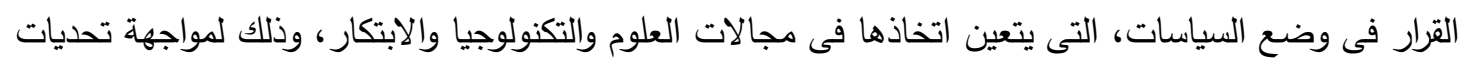

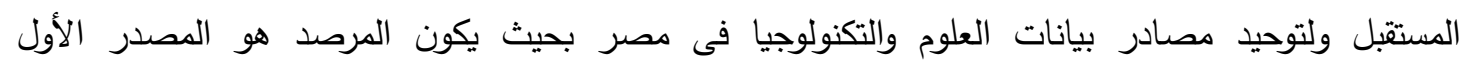
لمعلومات وبيانات العلوم والتكنولوجيا والابتكار لجميع الهيئات الدولية، مثل اليونسكو ومنظمة التتمية والتعاون لئن الاقتصادى، وغيرها من المنظمات الدولية. وقد لوحظ تطور الانفاق الإجمالي على البحث والتطوير والابتكار (GERD) في السنوات الأخيرة, فقد إرتفع من

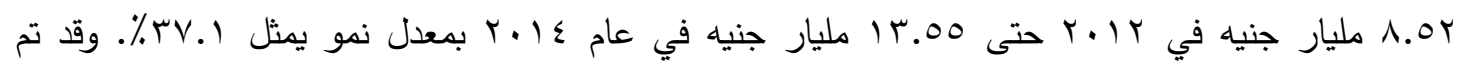
حساب الإنفاق لكل من قطاع التعليم العالي الممثل في الجامعات والقطاع الحكومى الممثل في المراكز البحثية

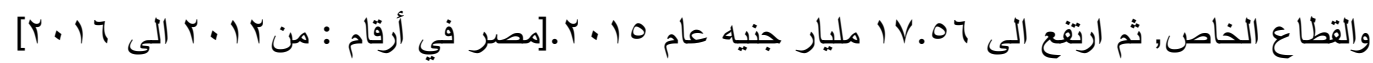
الانفاق على البحث العلمي كنسبة من الناتج المحلي الاجمالي (\%GDP)

\begin{tabular}{|c|c|}
\hline الانفاق & السنة \\
\hline. .19 & $r \ldots$ \\
\hline..$Y V$ & $r \ldots \varepsilon$ \\
\hline$. . r \leq$ & $r \ldots o$ \\
\hline.$r Y$ & $r \ldots r$ \\
\hline .rY & $r \ldots v$ \\
\hline..$T V$ & $r \ldots \Lambda$ \\
\hline$. . r \leqslant$ & $r \ldots q$ \\
\hline . . & $r .1$. \\
\hline س . . & $r .11$ \\
\hline .01 & $r .1 r$ \\
\hline .7 & $r .1 r$ \\
\hline.$V^{\prime}$ & $r .1 \varepsilon$ \\
\hline r. & r. \\
\hline
\end{tabular}

المصدر : بيانات تم جمعها من بيانات البنك الدولي سنوات مختلفة 


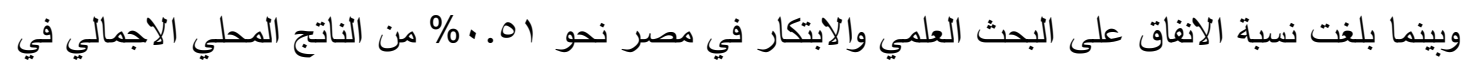

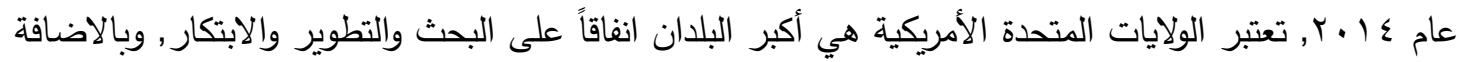

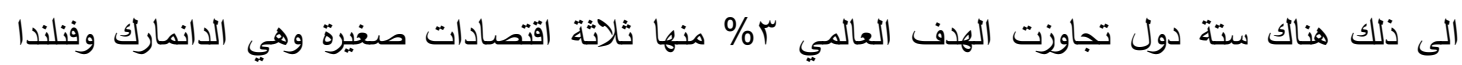

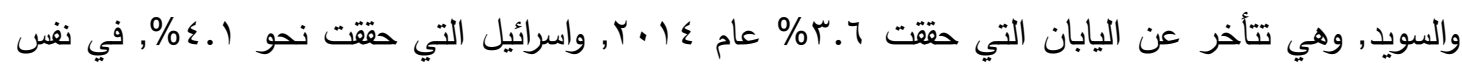

\section{معدل الانفاق على البحث والتطوير والابتكار في مصر وبعض دول العالم}

\section{خلال عام ـ I.}

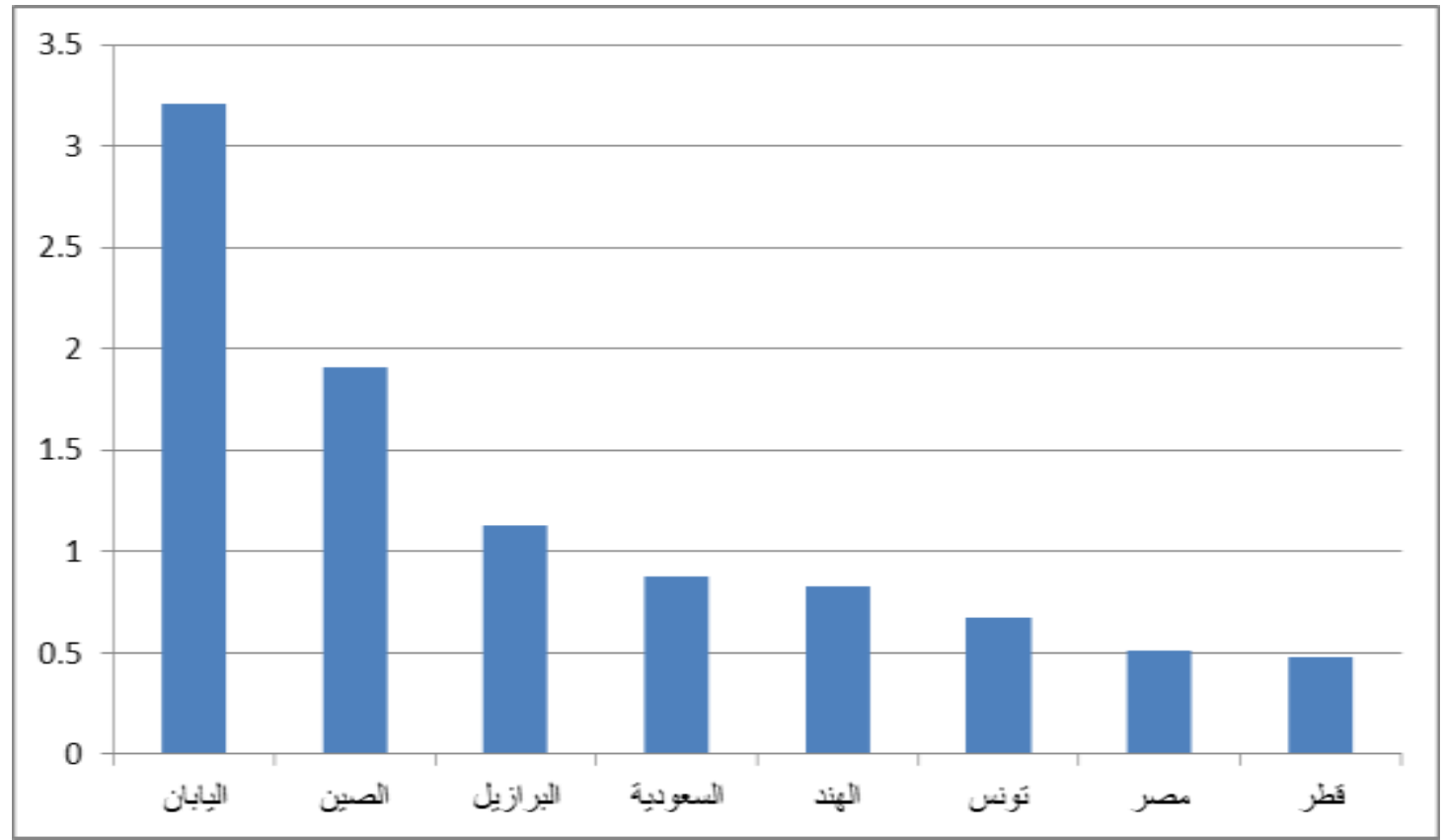

المصدر : اعداد الباحثة من خلال بيانات البنك الدولي

ويعتمد الانفاق على البحث والتطوير والابتكار في مصر على الانفاق الحكومي بنسبة كبيرة, بينما يتقلص دور

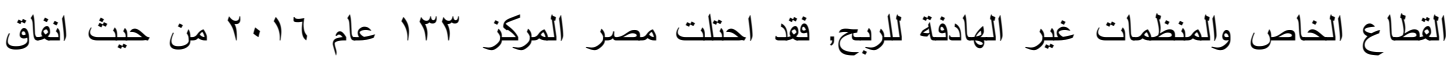

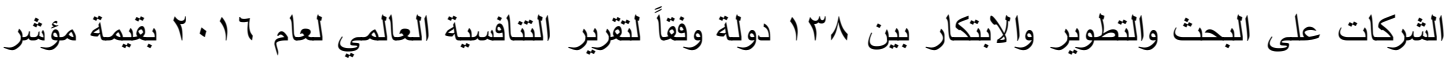

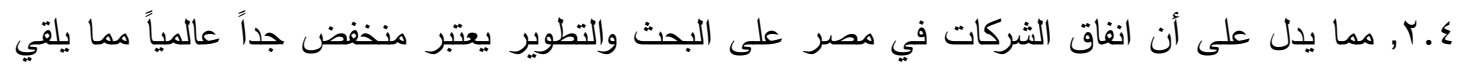
على عاتق الدولة بمسئولية الانفاق على البحث والتطوير , بينما تصل نسبة الانفاق الحكومي على البحث

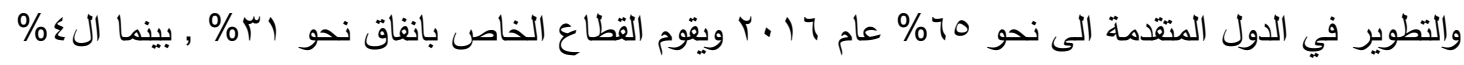

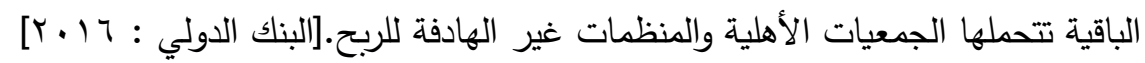


معل انفاق الثركات على البحث والتطوير والابتكار في مصر

في عدد من السنوات

\begin{tabular}{|c|c|c|}
\hline القيمة & المركز & السنة \\
\hline Y.T & 117 & $r+1 r / r+1 r$ \\
\hline r.o & Tr & $r+1 \leqslant / r+1 r$ \\
\hline r.r & ITr & $r+10 / r+1 \varepsilon$ \\
\hline r. $\varepsilon$ & Tr & $r .17 / r+10$ \\
\hline r. $\varepsilon$ & س & $r+1 V / r+19$ \\
\hline
\end{tabular}

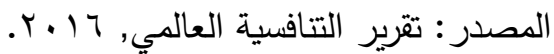

تتراوح قيمة المؤشر بين (1-1) درجات, يعبر الواحد عن التدنى التام فى مستوى مراكز البحث العلمى , و V

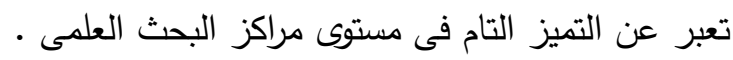
؟ - عوائد ومخرجات البحث العلمي في مصر

وبتتاول ما أنتجه مجال البحث العلمي من مخرجات كالأبحاث العلمية المنشورة وبراءات الاختراع الصادرة,

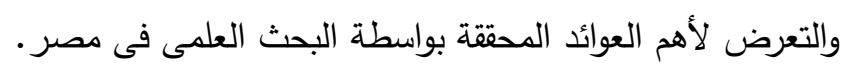
ج-1 الأبحاث العلمية المصرية المنثورة محلياً وعالمياً

يوضح الجدول رقم ( ) اتجاه عدد الأبحاث المصرية المنشورة فى المجلات العالمية نحو الارتفاع , ليسجل نحو

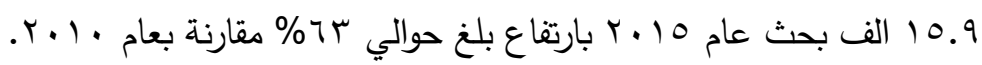
وقد احتلت الولايات المتحدة الأمريكية المرتبة الأولى على مستوى العالم من حيث عدد الأبحاث المنشورة فى

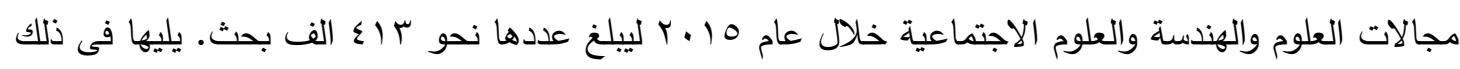

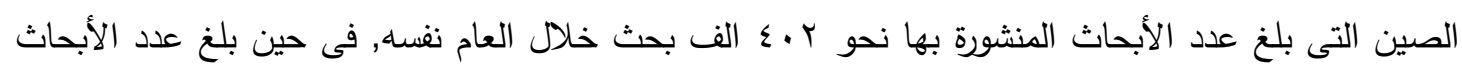

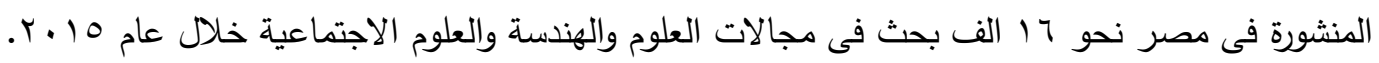


مقالات المجلات العلمية والتقنية لمصر

في عدد من السنوات

\begin{tabular}{|c|c|}
\hline المقالات العلمية والتقنية & السنة \\
\hline$r \leqslant V V$ & $r \ldots o$ \\
\hline rq17 & $r \ldots q$ \\
\hline$\leqslant \leqslant 77$ & $r \ldots v$ \\
\hline$\varepsilon \wedge 94$ & $r \ldots \Lambda$ \\
\hline TH人 & r...q \\
\hline $779 V$ & $r+1$. \\
\hline$V \vee \cdot \Lambda$ & $r .11$ \\
\hline А१९q & $r .1 r$ \\
\hline 9199 & $r+1 r$ \\
\hline $1.0 \times 7$ & $r+1 \leq$ \\
\hline 10197 & $r .10$ \\
\hline
\end{tabular}

المصدر : الجهاز المركزي للتعبئة العامة والاحصاء, مصر في أرقام, عدد من السنوات

مقارنة مصر بيعض دول العالم من حيث

\section{مقالات المجلات العلمية وإلتقنية عام ه بـ}

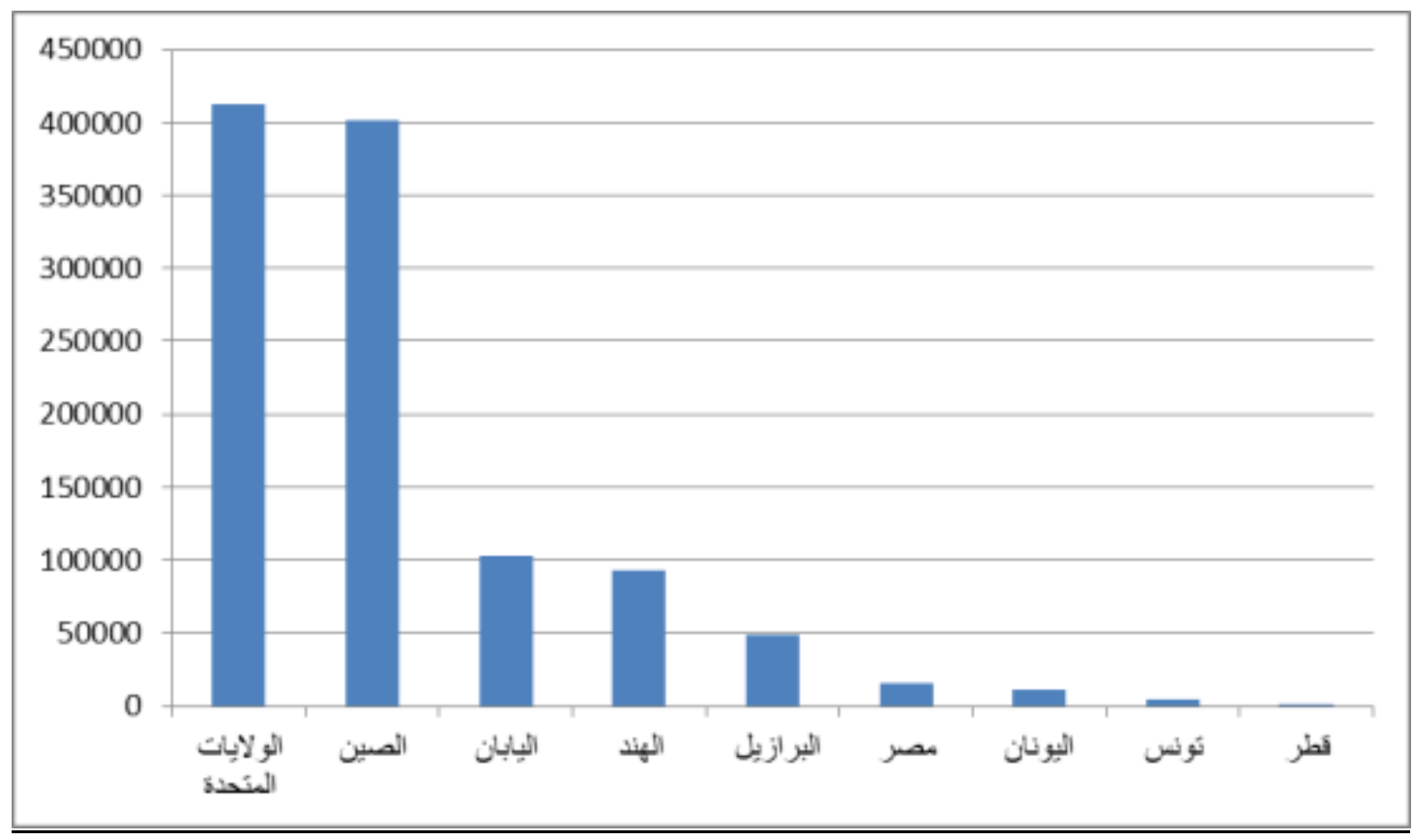

المصدر : تم جمع البيانات من تقارير البنك الدولي 


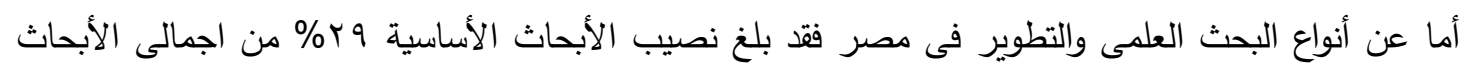

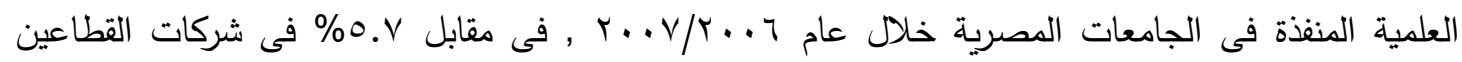
الخاص والأعمال العام خلال العام نغسه.

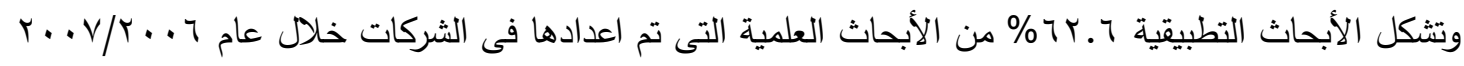

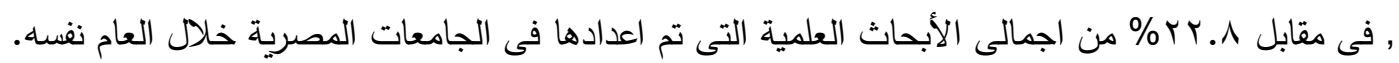

\section{ب-r ب براءات الاختراع كمقياس للقدرة التكنولوجية}

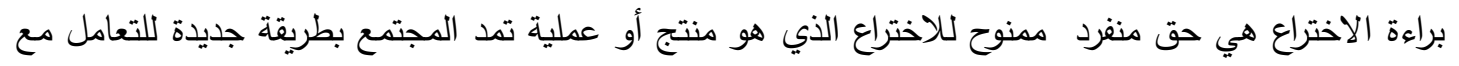
شئ موجود أو يعرض حلاً تقنياً جديداً لمشكلة قائمة, وذلك بناءً على تعريف مكتب براءوات الات الاختراع المصري.

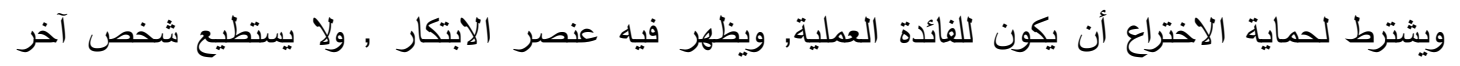

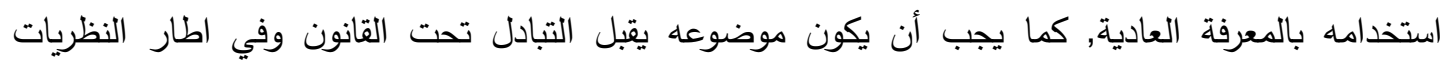

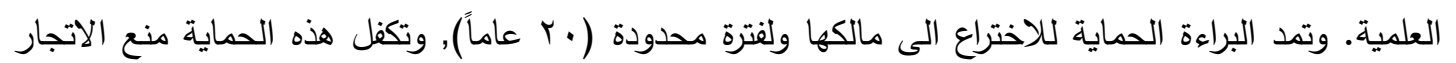

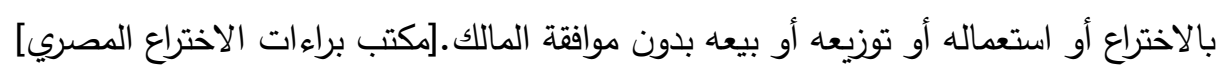
وقد اتجه نصيب مصر من اجمالى عدد براءات الاختراع الممنوحه من مكتب براءات الاختراع المصرى' نحو

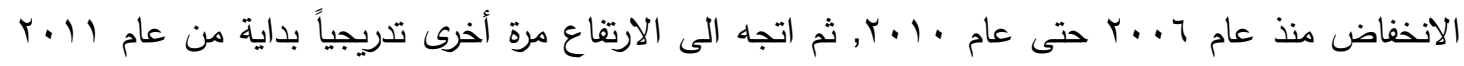

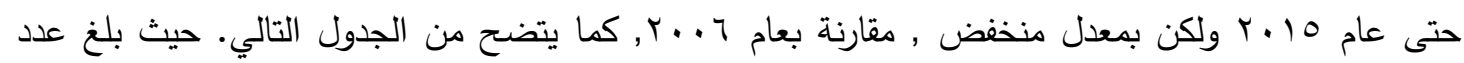

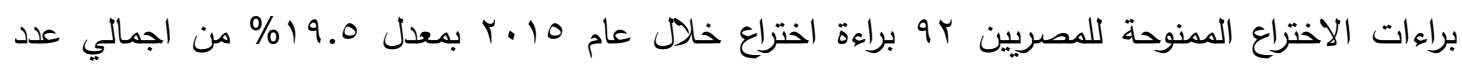

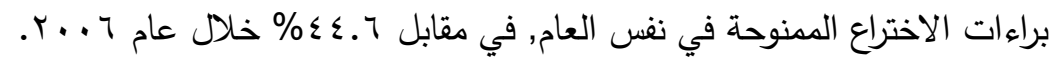

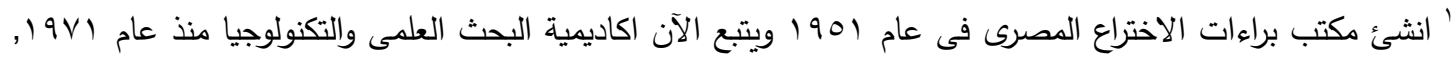

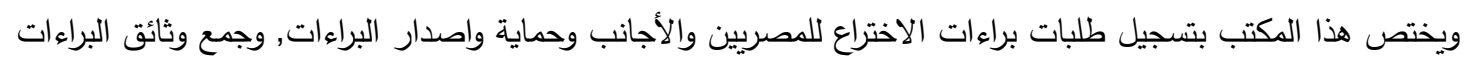

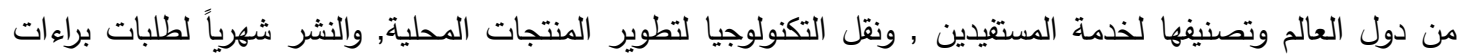
الاختراع والصادر منها والاجراءات اللازمة. 
تطور عدد براءات الاختراع الممنوحة من مكتب البراءات المصري

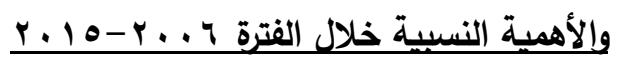

\begin{tabular}{|c|c|c|c|c|c|}
\hline 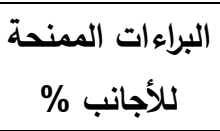 & البراءات الممنوحة & الاجمالي & البراءات الممنوحة & البراءات الممنوحة & السنة \\
\hline $00 . \varepsilon$ & $\varepsilon \varepsilon .7$ & . & VT & 01 & $r \ldots r$ \\
\hline VY. 9 & rV.I & 99 & Y) & $\wedge 1$ & $r \cdot v$ \\
\hline VV. 7 & YY.E & ודצr & rᄉ. & $\Lambda 1$ & $r \ldots \Lambda$ \\
\hline Ar.q & 18.1 & I & זדצ & 00 & $r \ldots q$ \\
\hline$\Lambda \Lambda . r$ & 11.1 & I & rAT & $\mu \wedge$ & $r .1$. \\
\hline$\Lambda \vee . \varepsilon$ & 1 T.7 & $\varepsilon \wedge \varepsilon$ & $\varepsilon r T$ & 71 & $r .11$ \\
\hline 10.0 & $1 \varepsilon .0$ & צTו & $0 \leq r$ & $q r$ & $r .1 r$ \\
\hline 11.0 & 11.0 & $\leqslant 70$ & rvq & $\Lambda 7$ & $r \cdot 1 r$ \\
\hline$\wedge \varepsilon .1$ & 10.9 & $\leqslant 10$ & $r \leq q$ & 97 & $Y, 1 \leq$ \\
\hline $1 . .0$ & 19.0 & $\Sigma V Y$ & rᄉ. & $q r$ & $r .10$ \\
\hline
\end{tabular}

المصدر : مصر في أرقام, 1 ب.

وقد استحوذ مجال الكيمياء والفلزات على النصيب الأكبر من اجمالي براءات الاختراع الممنوحة للمصريين خلال عام 0 • ب بنسبة •r\% يليها مجال الاحتياجات الانسانية بنسبة \% , في حين كان يستحوذ مجال الاحتياجات

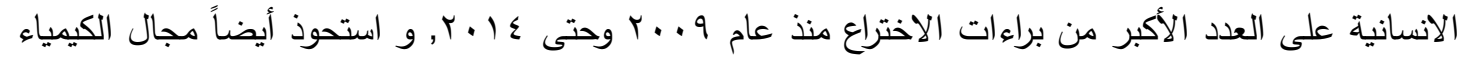

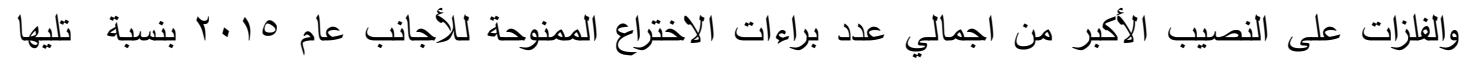
الاحتياجات الانسانية بنسبة

البراءات الممنوحة من مكتب براءات الاختراع المصري وفقاً للتصنيف الدولي

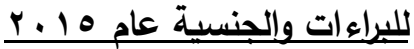

\begin{tabular}{|c|c|c|c|c|}
\hline المجموع & أجانب & مصريون & البيان & التصنيف * \\
\hline$v \cdot$ & $\varepsilon \vee$ & זr & الاحتياجات الانسانية & A \\
\hline १४ & $\checkmark v$ & r. & عمليات التشكيل والنقل & B \\
\hline 100 & IYA & rV & الكيمياء والفلزات & C \\
\hline 1. & 1. & . & النسيج والورق & D \\
\hline$\varepsilon \varepsilon$ & rv & v & المباني الثابتة & E \\
\hline rq & ro & $\varepsilon$ & الهندسة الميكانيكية & $F$ \\
\hline$\leq 9$ & rᄉ & 11 & الطبيعة والنوويات & G \\
\hline 11 & 11 & . & الكهرباء والاتصالات & H \\
\hline$\varepsilon V r$ & rᄉ. & 94 & \multicolumn{2}{|c|}{ الاجمالى } \\
\hline
\end{tabular}

* الرموز طبقاً للتصنيف الدولي الموحد للبراءات (IPC)

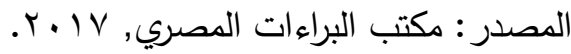




\section{الخلاصة}

مما سبق يمكن أن نستتتج ما يلي: - ما

تمثل المعرفة مورد متجدد يمكن الاعتماد عليه في تحقيق التتمية المستدامة عوضاً عن المنائ استضاب المواد الخام القائم الأن في أغلب الدول العربية اما مباشرة في الدول النفطية أو اشتقاقاً من فئن غيرها نتيجة للاعتماد على المعونات وتحويلات العاملين من هذه الدول.

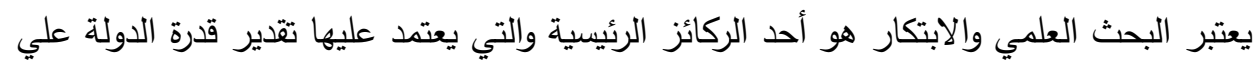

الانتقال الى مجتمع المعرفة.

يعتمد قياس جودة البحث العلمي والابتكار على مجموعة من المؤشرات الفرعية والتي يتم استخدامها في معظم المؤشرات العالمية لقياس جودة البحث العلمي والابتكار في البلدان المختلفة. للابتكار طابع مزدوج كما لوحظ في مختلف النظم , فهو كمورد يعامل كتكلفة يم تحديدها في البداية,

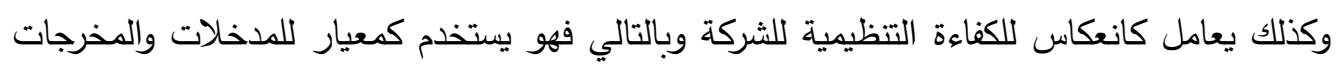
لتقييم كفاءة النظم الاقتصادية. يقدم التمويل لنظام البحث والتتمية والابتكار في مصر في المقام الأول من وزارة المالية استتاداً الى

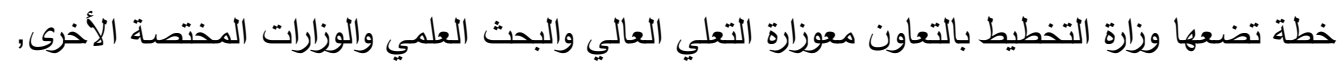

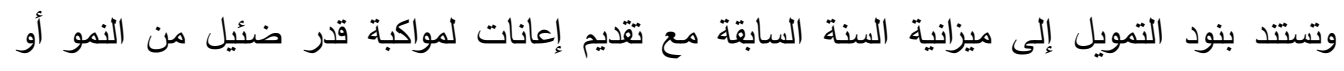

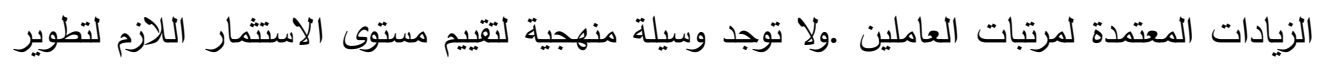
البنية الأساسية وشراء التكنولوجيات أو المعدات أو المستلزمات أو موارد المعرفة الجديدة. تحتاج مصر الى المزيد من دعم البحث العلمي والابتكار من خلال استخدام مجموعة من السياسات

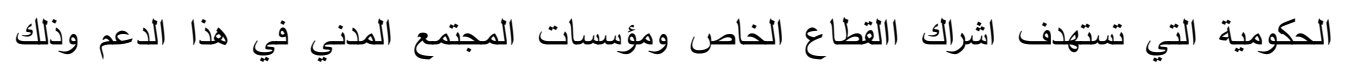
باستخدام مجموعة من الميزات والحوافز المالية والادارية.

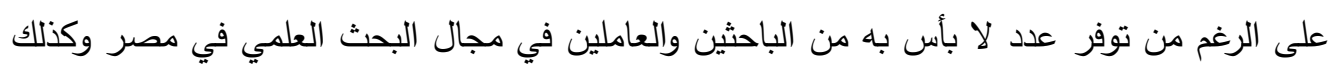

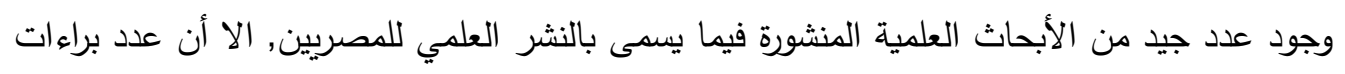

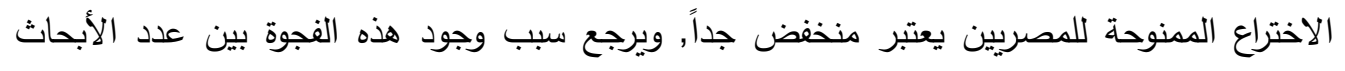

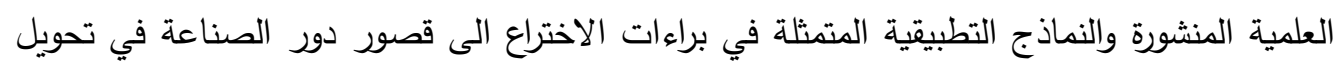
البحوث الجيدة لى منتجات يمكن تسويقها وتسجيلها كبراءات اختراع. لقد لوحظ طول الفترة المنقضية ما بين التقديم للحصول على براءة الاختراع وبين منحها خاصة لتهبة

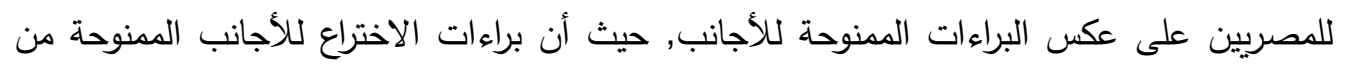
مكتب براءات الاختراع المصري تستغرق ما بين سنة الى ثلاث سنوات , أما البراءات الممنوحة

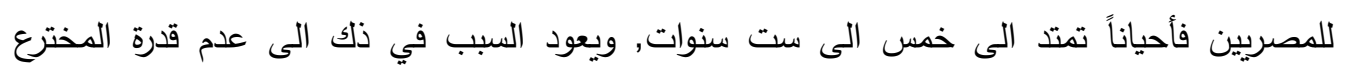

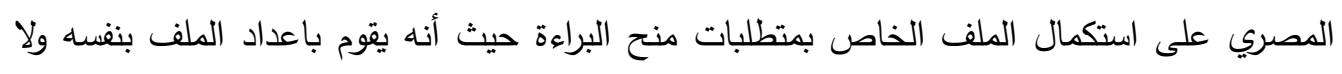

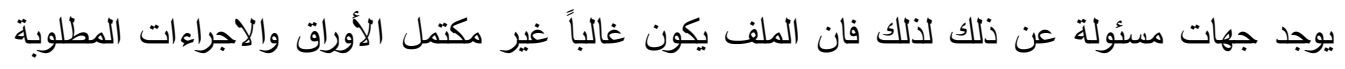
لمنح البراءة, أما الأجانب فهناك وكالات أجنبية في الدول المتقدمة تكون مسئولة عن اعداد تلك لكان الملفات والأوراق والاجراءات وبالتالي يتم تقديم الملف متكاملاً فلا يستغرق وقتاً طويلاً حتى يتم منح الأح 
ان اجراءات الاصلاح الاقتصادي التي شهدتها مصر في الآونة الأخيرة , وعلى رأسها تعويم الجنيه

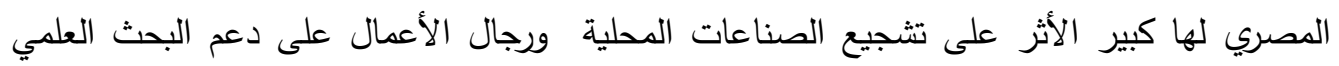
والابتكار لانتاج بعض السلع والمعدات المحلية رخيصة الثمن.

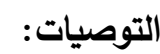

يجب الاعتماد على تأسيس نمط انتاج المعرفة في تحقيق التتمية المستدامة التي تستمر للأجيال القادمة بدلاً من الاعتماد على استتزاف الموارد النادرة وحرمان الأجيال القادمة منها.

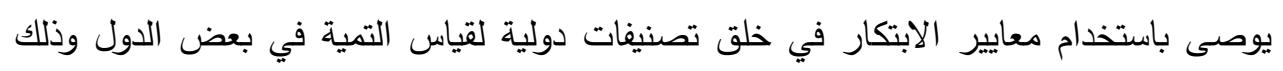
بسبب امكانية استخدامه كمعيار لكفاءة وانتاجية النظم الاقتصادية.

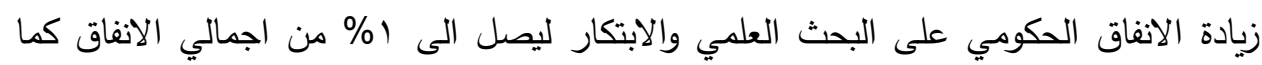
نص على ذلك الدستور , كما يجب تثجيع القطاع الخاص والمؤسسات الأهلية لتقديم التمويل

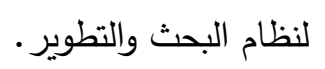
الاهتمام بالعنصر البشري والذي يعتبر هو اهم ركائز مجتمع المعرفة وذلك من خلال الاهتمام

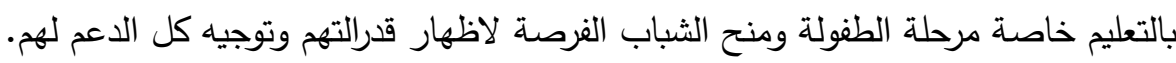

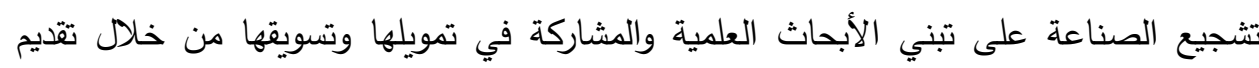

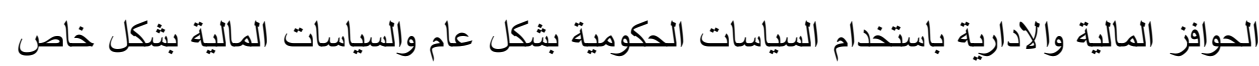

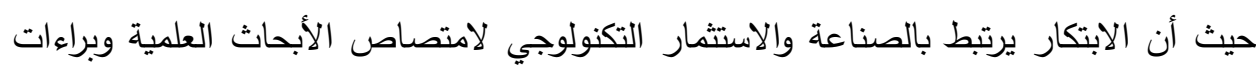
الاختراع وترجمتها الى منتجات نهائية.

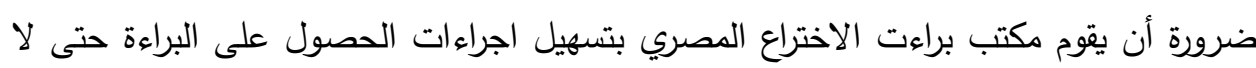
تستغرق وقتاً طويلاً حتي يتم الانتهاء من تسجيل البراءة. 


\section{قائمة المراحع}

اولاً : المراجع العربيه

تقرير التمية الانسانية العربية V . . r.

التقرير الاقتصادي العربي الموحد, 10 • r.

تقرير اليونسكو, ع أ.

ايمان سمير البيج, البحث العلمي في الوطن العربي الواقع والآفاق, دراسة مقارنة, معهد الفتح الاسلامي

قسم الدراسات التخصصية شعبة الاقتصاد الاسلامي, ی ^. . r.

حمد اللحيدان، الاقتصاد الريعي والاقتصاد المعرفي، جريدة الرياض الإلكترونية، ب شباط r I ب. .

عاصم شحادة على, تمويل البحث العلمي وأثره في التمية البشرية: ماليزيا نموذجاً, الجامعة الاسلامية

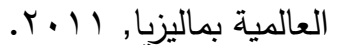

محسن خضر , عوائق البحث العلمى, كلية التربية, جامعة عين شمس, 9 ـ. . .

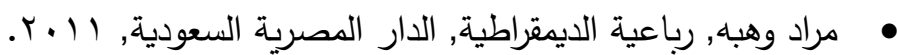

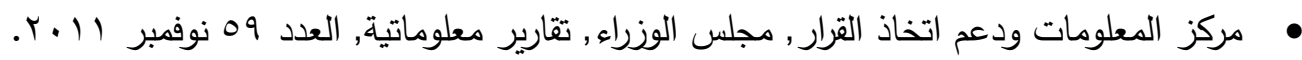

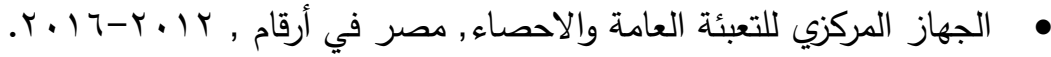

• مكتب البراءات المصري, مصر في ارقام IV • •

• مراد علةًّ, جاهزية الدول العربية للاندماج في اقتصاد المعرفة - دراسة نظرية تحليلية - - كلية العلوم

الاقتصادية والتسيير والعلوم التجارية، جامعة الجلفة -الجزائر , I I ـ ؟.

• منظمة التعاون والتتمية في الميدان الاقتصادية والبنك الدولي للإنثاء والتعمير/البنك الدولي، مراجعات

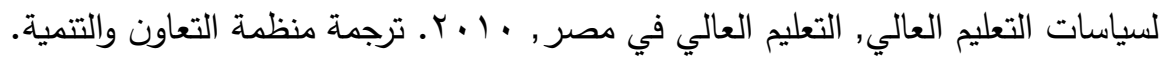
• مؤسسة محمد بن راثد آل مكتوم, برنامج الأمم المتحدة الانمائى, مؤشر المعرفة العربى, المنهجية والمفاهيم

.$r \cdot 10$

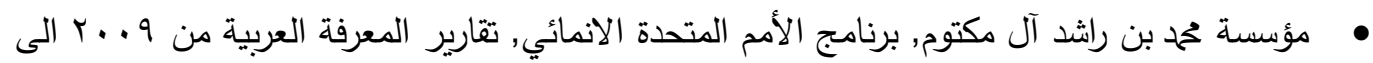

.$Y \cdot 17$ 
- Dragomir Sundać, Irena Fatur Krmpotić, Knowledge Economy Factors and the Development of Knowledge-based Economy, Croatian Economic Survey : Vol. 13 : No. 1 : April 2011 : pp. 105-141.

- VLADIMÍR ZÍTEK - VIKTORIE KLÍMOVÁ, KNOWLEDGE ECONOMY AND KNOWLEDGE INFRASTRUCTURE, International Conference On Applied Economics - ICOAE 2011821

- Jindřich Soukup, KNOWLEDGE ECONOMY AND INNOVATION INDICES:THEIR CONCORDANCE AND DIVERSITY, The 7th International Days of Statistics and Economics, Prague, September 19-21, 2013

- NÁRODOHOSPODÁŘSKÝ OBZOR, HUMAN CAPITAL AND INNOVATIVENESS AS MEANS TO BRIDGING, DEVELOPMENT GAPS. POLAND AND THE CZECH REPUBLIC AS CASE STUDIES, VOL. 10, ISSUE 3,2010

- Soumitra Dutta, Bruno Lanvin, The Global Innovation Index 2013, The Local Dynamics of Innovation, 2013. 